\title{
Modeling Fall Propensity in Parkinson's Disease: Deficits in the Attentional Control of Complex Movements in Rats with Cortical-Cholinergic and Striatal-Dopaminergic Deafferentation
}

\author{
Aaron Kucinski, ${ }^{1}$ Giovanna Paolone, ${ }^{1}$ Marc Bradshaw, ${ }^{1}$ Roger L. Albin, ${ }^{2,3}$ and Martin Sarter ${ }^{1,4}$ \\ ${ }^{1}$ Department of Psychology, ${ }^{2}$ Neurology Service and Geriatric Research, Education and Clinical Center, Veterans Administration Ann Arbor Healthcare \\ System, ${ }^{3}$ Department of Neurology, and ${ }^{4}$ Neuroscience Program, University of Michigan, Ann Arbor, Michigan 48109
}

\begin{abstract}
Cognitive symptoms, complex movement deficits, and increased propensity for falls are interrelated and levodopa-unresponsive symptoms in patients with Parkinson's disease (PD). We developed a test system for the assessment of fall propensity in rats and tested the hypothesis that interactions between loss of cortical cholinergic and striatal dopaminergic afferents increase fall propensity. Rats were trained to traverse stationary and rotating rods, placed horizontally or at inclines, and while exposed to distractors. Rats also performed an operant Sustained Attention Task (SAT). Partial cortical cholinergic and/or caudate dopaminergic deafferentation were produced by bilateral infusions of $192 \mathrm{IgG}$-saporin (SAP) into the basal forebrain and/or 6-hydroxydopamine (6-OHDA) into the caudate nucleus, respectively, modeling the lesions seen in early PD. Rats with dual cholinergic-dopaminergic lesions (DL) fell more frequently than SAP or 6-OHDA rats. Falls in DL rats were associated with incomplete rebalancing after slips and low traversal speed. Ladder rung walking and pasta handling performance did not indicate sensorimotor deficits. SAT performance was impaired in DL and SAP rats; however, SAT performance and falls were correlated only in DL rats. Furthermore, in DL rats, but not in rats with only dopaminergic lesions, the placement and size of dopaminergic lesion correlated significantly with fall rates. The results support the hypothesis that after dual cholinergic-dopaminergic lesions, attentional resources can no longer be recruited to compensate for diminished striatal control of complex movement, thereby "unmasking" impaired striatal control of complex movements and yielding falls.
\end{abstract}

\section{Introduction}

Research using animal models of Parkinson's disease (PD) has focused on reproducing the motor deficits that result from extensive loss of nigrostriatal dopaminergic neurons, on evaluating treatments for this deficit, and on the modeling and treatment of levodopa-induced dyskinesia (Zigmond and Stricker, 1989; Montoya et al., 1991; Lundblad et al., 2002, 2004; Meredith and Kang, 2006; Simola et al., 2007). However, up to two-thirds of PD patients suffer from a range of nonmotor symptoms that include cognitive impairments and deficient control of complex movements, gait and balance (Langston, 2006; Cools et al., 2010; Litvan et al., 2012). These patients are also prone for falls (Balash et al., 2005). Falls and related movement errors, including the freezing

\footnotetext{
Received June 16, 2013; revised Sept. 4, 2013; accepted Sept. 10, 2013.

Author contributions: R.L.A. and M.S. designed research; A.K. and G.P. performed research; M.B. contributed unpublished reagents/analytic tools; A.K. analyzed data; R.L.A. and M.S. wrote the paper.

This work was supported by the Michael J. Fox Foundation for Parkinson's Research (M.S.). We thank Kazimir Smolenski for assisting in the analysis of the lesions, Elizabeth Ronan for conducting pasta handling tests, and Dr. Timothy Johnson (Department of Biostatistics, University of Michigan) for advising us on the selection of statistical tests.

The authors declare no competing financial interests.

Correspondence should be addressed to Dr. Martin Sarter, University of Michigan, Department of Psychology, 530 Church Street, 4032 East Hall, Ann Arbor, Ml 48109-8862. E-mail: msarter@umich.edu.

DOI:10.1523/JNEUROSCI.2545-13.2013

Copyright $\odot 2013$ the authors $\quad 0270-6474 / 13 / 3316522-18 \$ 15.00 / 0$
}

of gait, have been associated with attenuated attentional capacities (Balash et al., 2005; Wood et al., 2002; Allcock et al., 2009; Lord et al., 2010; Naismith et al., 2010). These levodopaunresponsive symptoms often are disabling (Johnell et al., 1992), yet their underlying neuronal mechanisms are not well understood (McDowell and Chesselet, 2012).

In $\mathrm{PD}$, decreases in cholinergic terminals may occur as early as the degeneration of midbrain dopaminergic neurons (Nakano and Hirano, 1984; Bohnen and Albin, 2009; Shimada et al., 2009). Cholinergic cell loss progresses most severely in PD patients developing dementia (Bohnen et al., 2003, 2012). Importantly, reduced levels of cortical and thalamic acetylcholinesterase (AChE), which reflects cholinergic terminal integrity, but not of nigrostriatal dopaminergic terminal integrity, differentiated PD fallers from nonfallers (Bohnen et al., 2009; Bohnen and Albin, 2011). We hypothesized that an animal model of fall propensity in PD would need to reproduce loss of cortical cholinergic as well as striatal dopaminergic projections. The former is well established to cause impairments in attention (McGaughy et al., 1996; Turchi and Sarter, 2000; Dalley et al., 2004; Botly and De Rosa, 2009), whereas the latter interferes with the execution of repetitive, automated action patterns (Graybiel, 2008; Redgrave et al., 2010). We further hypothesized that enhanced attentional supervision of complex movements, gait and balance compensates for 
Table 1. Timeline of experiments

\begin{tabular}{|c|c|c|c|c|c|c|}
\hline & \multicolumn{2}{|l|}{ Prelesion } & \multirow[b]{2}{*}{ Lesion recovery: $45-60 \mathrm{~d}$} & \multicolumn{3}{|l|}{ Postlesion } \\
\hline & $1-30 d$ & $30-45 d$ & & $60-95 d$ & $95-125 d$ & $125-140 d$ \\
\hline Water delivery regimen & Restricted & Restricted & Ad libitum & Restricted & Ad libitum & Ad libitum \\
\hline Daily SAT training/practice & 10:00 A.M. - 2:00 P.M. & 10:00 A.M. - 2:00 P.M. & NA & 10:00 A.M. - 2:00 P.M. & NA & NA \\
\hline Daily MCMCT testing & NA & 3:00 P.M. - 6:00 P.M. & NA & 3:00 P.M. - 6:00 P.M. & NA & NA \\
\hline Vermicelli test & NA & NA & NA & NA & NA & 3:00 P.M. - 6:00 P.M. \\
\hline
\end{tabular}

NA, Not applicable.

deficits in striatal functions (Stam et al., 1993; Lord et al., 2010). As a result of dual cholinergic-dopaminergic damage, such compensatory supervision may no longer be available, thereby increasing the risk for severe movement errors and falls (Yarnall et al., 2011; van Schouwenburg et al., 2012).

To test this hypothesis, we determined the effects of partial striatal dopaminergic, cortical cholinergic, and combined cholinergic-dopaminergic deafferentation on the performance of a newly developed test for the assessment of complex movements, gait and balance, and falls (see Materials and Methods for the development of the apparatus and justification of lesions). Animals also performed a Sustained Attention Task (SAT) (McGaughy and Sarter, 1995; Demeter et al., 2008, 2011, 2013; Howe et al., 2013). The present evidence indicates that dual cholinergic-dopaminergic lesions increase the rate of falls in situations requiring the attentional control of complex movements, that attentional impairments and fall propensity are correlated, and that cholinergic deafferentation unmasks the contributions of dorsal striatal dopamine to complex movement, balance, and gait control.

\section{Materials and Methods}

Animals and animal housing. Adult male Sprague Dawley rats (Harlan), 3-6 months of age and weighing between 275 and $475 \mathrm{~g}$ at the beginning of the experiments, were used. Animals were individually housed in opaque single standard cages $(27.70 \mathrm{~cm} \times 20.30 \mathrm{~cm})$ in a temperaturecontrolled $\left(23^{\circ} \mathrm{C}\right)$ and humidity-controlled $(45 \%)$ environment under a $12 \mathrm{~h} \mathrm{light/dark}$ (12:12 LD) schedule. Animals were handled extensively before the beginning of task training. Rats were water-deprived by limiting access to a $15 \mathrm{~min}$ period after each SAT training session. Water was also provided as a reward for correct responses during SAT performance (see below). On days not tested, the duration of water access was increased to $30 \mathrm{~min}$. Food (Rodent Chow; Harlan Teklad) was available ad libitum. Body weights were recorded weekly. All procedures were conducted in adherence with protocols approved by the University Committee on Use and Care of Animals at the University of Michigan and in laboratories accredited by the Association for Assessment and Accreditation of Laboratory Animal Care.

Number of animals and experimental timeline. The evidence reported here is based on $N=44$ rats $(n=11$ rats per group [sham-lesioned; striatal 6-hydroxydopamine (6-OHDA)-lesioned; basal forebrain 192 IgG-saporin-lesioned; rats with lesions of both striatal dopaminergic and cortical cholinergic neurons; these groups henceforth are termed "shams," "6-OHDA," "SAP," and DUAL, "DL"]). These rats underwent the entire battery of the Michigan Complex Motor Control Test (MCMCT) and met histological verification criteria. The average body weights of these animals, recorded during the final week of postlesion MCMCT testing, were as follows (mean \pm SEM): sham, $372.00 \pm 10.24$ g; 6-OHDA, $380.09 \pm 5.18 \mathrm{~g}$; SAP, $344.27 \pm 12.24 \mathrm{~g}$; DL, $361 \pm 11.28 \mathrm{~g}$ $\left(F_{(3,43)}=2.08, p=0.12\right)$. An additional 7 rats of the original 51 animals ( 4 shams, $3 \mathrm{DL}$ ) were added to the group of rats tested in the vermicelli test (total number of animals used for this test: 8 shams, $7 \mathrm{DL}$ ).

Table 1 provides a survey of the timeline of experiments. Rats were housed in their individual home cages for at least 2 weeks with ad libitum access to water before 1 week of gradual restriction to $15 \mathrm{~min}$ of water access (successive reduction to $22,12,8,5,3,1$, and $0.25 \mathrm{~h}$ ). SAT training
Table 2. Postsurgery MCMCT testing sequence

\begin{tabular}{|c|c|c|c|c|c|}
\hline Day & Trial type & $\begin{array}{l}\text { Rotating } \\
\text { (10 rpm cc or cw) }\end{array}$ & $\begin{array}{l}\text { Incline } \\
\left({ }^{\circ}\right)\end{array}$ & Distractor & $\begin{array}{l}\text { No. of } \\
\text { trials }\end{array}$ \\
\hline \multirow[t]{2}{*}{1} & Plank shaping & & 0 & & 2 \\
\hline & Plank & & 0 & & 3 \\
\hline \multirow[t]{2}{*}{2} & Rod shaping & & 0 & & 2 \\
\hline & Rod & & 0 & & 3 \\
\hline \multirow[t]{2}{*}{3} & Plank & & 22.5 & & 3 \\
\hline & Rod & & 22.5 & & 3 \\
\hline \multirow[t]{2}{*}{4} & Rod & cc & 0 & & 3 \\
\hline & Rod & cc & 22.5 & & 3 \\
\hline \multirow[t]{2}{*}{5} & Rod/door frame shaping & cc & 0 & Door frame & 2 \\
\hline & Ladder task & & & & 3 \\
\hline 6 & Rod & $\mathrm{CW}-\mathrm{cc}-\mathrm{CW}-\mathrm{CC}$ & 0 & & 4 \\
\hline 7 & Rod & $c W-c c-c W-c c$ & 22.5 & & 4 \\
\hline \multirow[t]{2}{*}{8} & Rod & $c c$ & 0 & Door frame & 2 \\
\hline & Ladder task & & & & 3 \\
\hline \multirow[t]{2}{*}{9} & Plank & & 35 & & 3 \\
\hline & Rod & & 35 & & 3 \\
\hline 10 & Rod & $c c$ & 35 & & 4 \\
\hline 11 & Rod & $\mathrm{CW}-\mathrm{Cc}-\mathrm{CW}-\mathrm{CC}$ & 35 & & 4 \\
\hline 12 & $\begin{array}{l}\text { Rod/froot Loop distractor } \\
\text { shaping }\end{array}$ & & 0 & Froot Loop on right side & 3 \\
\hline 13 & $\begin{array}{l}\text { Rod/froot Loop distractor } \\
\text { shaping }\end{array}$ & 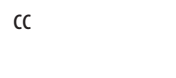 & 0 & Froot Loop on right side & 3 \\
\hline 14 & Rod & $c c$ & 0 & Froot Loop on right side & 3 \\
\hline 15 & Rod & $\mathrm{CW}-\mathrm{Cc}-\mathrm{CW}-\mathrm{cc}$ & 0 & & 4 \\
\hline 16 & Rod & $\mathrm{cW}$ & 0 & Froot Loop on right side & 3 \\
\hline 17 & Rod & $\mathrm{CW}-\mathrm{cc}-\mathrm{CW}-\mathrm{Cc}$ & 22.5 & & 4 \\
\hline 18 & Rod & $c c$ & 0 & Froot Loop on left side & 3 \\
\hline 19 & Rod & $\mathrm{CW}-\mathrm{Cc}-\mathrm{CW}-\mathrm{cc}$ & 35 & & 4 \\
\hline 20 & Rod & $\mathrm{cW}$ & 0 & Froot Loop on left side & 3 \\
\hline
\end{tabular}

then started and occurred daily until a performance criterion was reached (see below; $\sim 1.5$ months). Prelesion MCMCT training began when the animals reached the final stage of SAT. SAT training continued daily while animals underwent testing of the prelesion MCMCT sequence.

Pilot experiments indicated that MCMCT performance is unaffected by the presence or absence of water deprivation; therefore, rats were trained or tested on SAT on the same days that testing on the MCMCT and ladder tasks took place. SAT sessions were scheduled daily between 10:00 A.M. and 2:00 P.M. Rats were given ad libitum access to water for 15 min immediately after the completion of the SAT session. MCMCT and ladder testing occurred between 3:00 P.M. and 6:00 P.M. on the same days (beginning at least $1 \mathrm{~h}$ after completion of SAT). Data from SAT sessions on the final $3 \mathrm{~d}$ of MCMCT practice before surgery were used for prelesion analysis of performance. After receiving lesions, the animals recovered for 2 weeks. During the first $7 \mathrm{~d}$ of recovery, rats were given ad libitum access to water followed by $7 \mathrm{~d}$ of gradual water deprivation to 15 min of daily access (as described above). Postlesion SAT and MCMCT testing then resumed. The MCMCT postlesion test sequence consisted of $20 \mathrm{~d}$ of trials and is described below (Table 2). All animals completed this sequence in 25-35 d. SAT performance data from during the final $3 \mathrm{~d}$ of MCMCT testing were used for postlesion analyses. Upon finishing the MCMCT sequence, rats were given ad libitum access to water (with no further SAT testing). The vermicelli test was conducted between 1 and 2 
months later. These animals were given ad libitum access to water throughout vermicelli testing. Vermicelli testing was conducted between 3:00 P.M. and 6:00 P.M.

SAT. Evidence in support of the validity of the SAT, in terms of generating measures of sustained attentional capacity in mice, rats, and humans, has been previously described (McGaughy and Sarter, 1995; Demeter et al., 2008, 2013). The SAT also taxes the ability to shift between states of perceptual attention and cue-directed behavior (Howe et al., 2013). Tonic and phasic components of right-hemispheric cholinergic activity mediate attentional control and attentional mode shifts, respectively, during SAT performance (Demeter et al., 2011; St Peters et al., 2011; Howe et al., 2013).

Apparatus. Training and testing were conducted using 12 operant chambers (MED Associates) housed within individual sound-attenuating cubicles. Each chamber was equipped with two retractable levers, a central panel white light $(2.8 \mathrm{~W})$, and a water dispenser located on the same wall as the panel lights and levers capable of administering $45 \mu \mathrm{l}$ of water per delivery. Signal presentation, lever operation, reinforcement delivery, and data collection were controlled by a Pentium PC and Med-PC for Windows software (version 4.1.3; MED Associates).

Acquisition. Water-deprived rats were initially trained to press a lever for a water reward in accordance with a modified fixed ratio-1 (FR1) schedule for water reinforcement. During this phase of training, any lever press resulted in the delivery of water. Typically, the animals do not exhibit a side bias with regard to which lever is pressed; however, if one lever was pressed $>5$ times in succession, the FR1 schedule is modified to require the animal to press the opposite lever before the next reward can be obtained. After 3 consecutive days with $>120$ reinforced lever presses each, the rats began training to discriminate between a signal ( $1 \mathrm{~s}$ illumination of the central panel light) and a nonsignal (no illumination) event. Two seconds (s) after a signal or nonsignal event, both levers were extended into the operant chamber and remain extended for $4 \mathrm{~s}$ or until a lever was pressed. If no press occurred after $4 \mathrm{~s}$, the levers retracted and an omission was scored. Immediately after a response (either correct or incorrect), both levers were retracted and the variable intertrial interval (ITI; $12 \pm 3 \mathrm{~s}$ ) was reset. On signal trials, a response on the left lever was reinforced and termed a "hit," whereas a response on the right lever was not reinforced and termed a "miss." On nonsignal trials, a response on the right lever was reinforced and termed a "correct rejection," whereas a response on the left lever was not reinforced and termed a "false alarm." Animals received water rewards only for correct responses $(40-45 \mu \mathrm{l}$ for each hit and correct rejection), whereas incorrect responses (misses and false alarms) were not rewarded. To eliminate the possibility of a selection bias, half of the animals were trained with the opposite pattern. Signal and nonsignal events were presented in pseudorandom order for 81 trials each (total of 162 trials) per session. During this phase of training, incorrect responses were followed by correction trials in which the trial was repeated. After three consecutive incorrect responses on correction trials, the animal underwent a forced trial in which the lever was extended for $90 \mathrm{~s}$ or until the animal made a response. If the forcedchoice trial was a signal trial, the signal light remained illuminated for as long as the lever was extended. The house light was not illuminated during this training stage. Animals progressed to the subsequent step of shaping if they responded correctly to $\geq 59 \%$ of both signal and nonsignal trials for 3 consecutive days.

During the third phase of shaping, multiple signal durations $(500,50$, and $25 \mathrm{~ms}$ ) were introduced and the ITI was reduced to $9 \pm 3 \mathrm{~s}$. Correction and forced-choice trials were also eliminated. Sessions were divided into three blocks of 54 trials each with all signal durations occurring randomly 9 times per block. Trial type and signal duration continued to be pseudorandomly determined for each trial. Session length was set at 40 min to allow for post hoc analysis of performance over five blocks ( 8 min per block). The pseudorandom selection of trial type (signal vs nonsignal) and signal duration was designed to ensure that approximately one-half of the trials per block were signal trials and that equivalent numbers of 500, 50, and $25 \mathrm{~ms}$ signals were presented during each block. After at least $5 \mathrm{~d}$ of stable performance, defined by at least $70 \%$ hits to 500 ms signals, $70 \%$ correct rejections, and $<20 \%$ omissions, animals began training in the final version of the task. The final version was identical to the previous training stage except that the house light was illuminated throughout the session. The addition of the illuminated house light represents a crucial element of testing sustained attention as it requires the animal to constrain its behavior and focus on the central panel light during task performance.

Criterion performance for advancement to receiving lesions was defined as an average of $>60 \%$ hits to $500 \mathrm{~ms}$ signals, $>70 \%$ correct rejections, and $<20 \%$ omissions for three consecutive sessions. Rats reached this criterion either by the time prelesion MCMCT training was complete (which commenced once the animals reached the final stage of SAT training) or within $5 \mathrm{~d}$ after completion of MCMCT training.

Measures of SAT performance. The following behavior measures were recorded during each SAT session: hits, misses, false alarms, correct rejections, and omissions. Misses and false alarms are the inverse of hits and correct rejections, respectively. The relative number of hits (hits/hits + misses) (percentage hits) were calculated for each signal length as well as the relative number of correct rejections (correct rejections/correct rejections + false alarms). In addition, an overall measure of attentional aptitude, the SAT score, that integrates both the relative number of hits (h) and the relative number of false alarms (f), was also determined at each signal duration. The SAT score was calculated using the following formula: $(h-f) /\left[2(h+f)-(h+f)^{2}\right]$. This index differs from the sensitivity index (Frey and Colliver, 1973) in that the former is based on the relative number of hits and false alarms as opposed to the probabilities for hits and false alarms. Thus, SAT scores are not confounded by errors of omission. SAT scores ranged from 1.0 to -1.0 , with 1.0 indicating that all responses were hits and correct rejections, 0 indicating an inability to discriminate between signal and nonsignal events, and -1.0 indicating that all responses were misses and false alarms. Errors of omission were recorded separately. Performance measures were calculated for each of the five task blocks.

\section{MCMCT}

Rationale guiding the development of the apparatus. The attentional causes of falls in PD patients and the elderly concern primarily the limited attentional resources available for the supervision of complex movement and the shift of attentional resources away from assisting subjects to move across complex surfaces, such as stairs. Such attention shifts may be triggered by unexpected events and competing tasks (e.g., LaPointe et al., 2010). In PD patients, freezing of gait and loss of balance often initiate a sequence of events that begins with attentional distraction and ends with a fall (e.g., Allcock et al., 2009; Lord et al., 2010; Naismith et al., 2010). PD patients prone to falls also exhibit postural control deficits when confronted with complex surfaces, such as stairs, and they generally exhibit slower walking speeds, shorter strides, and other kinematic weaknesses compared with patients not prone to falls (Cole et al., 2010, 2011; Nilsson et al., 2012). In the presence of a limited attentional capacity for assisting movement, interactions between postural instability and inefficient compensatory postural control in response to mishaps contribute to falls (Hall et al., 2011; O'Halloran et al., 2011). This apparatus was intended to reveal interactions between impairments in complex movement, gait and balance, and attentional control deficits, yielding freezing of movement, loss of balance and poor rebalancing skills after movement errors, and, thus, falls.

The design of the MCMCT was inspired by established beam traversal or elevated platform tests (Wallace et al., 1980; Drucker-Colín and García-Hernández, 1991; Fleming, 2009). Such tests reveal the efficiency of movement across runways with limited width and often placed at an incline. For example, mice with dopaminergic depletions, or expressing disease-associated genes found in familial PD, traverse beams at a slower rate and require more steps (Hwang et al., 2005; Lu et al., 2009). However, established beam traversal tasks do not seem to generate falls as they do not sufficiently tax control of complex movements or attentional supervision of movement, and they lack explicit distractors. Our apparatus (Fig. 1) specifically taxes the ability to rapidly correct movement errors when traversing complex rotating surfaces (square rods). Traversing rotating rods requires exquisite gait control, carefully timed and precisely placed weight-shifting steps, and nearly perfect limb coordination.

Apparatus. The apparatus consists of a U-shaped central rib with a start platform on one end and a cradle for a home cage on the other. The 


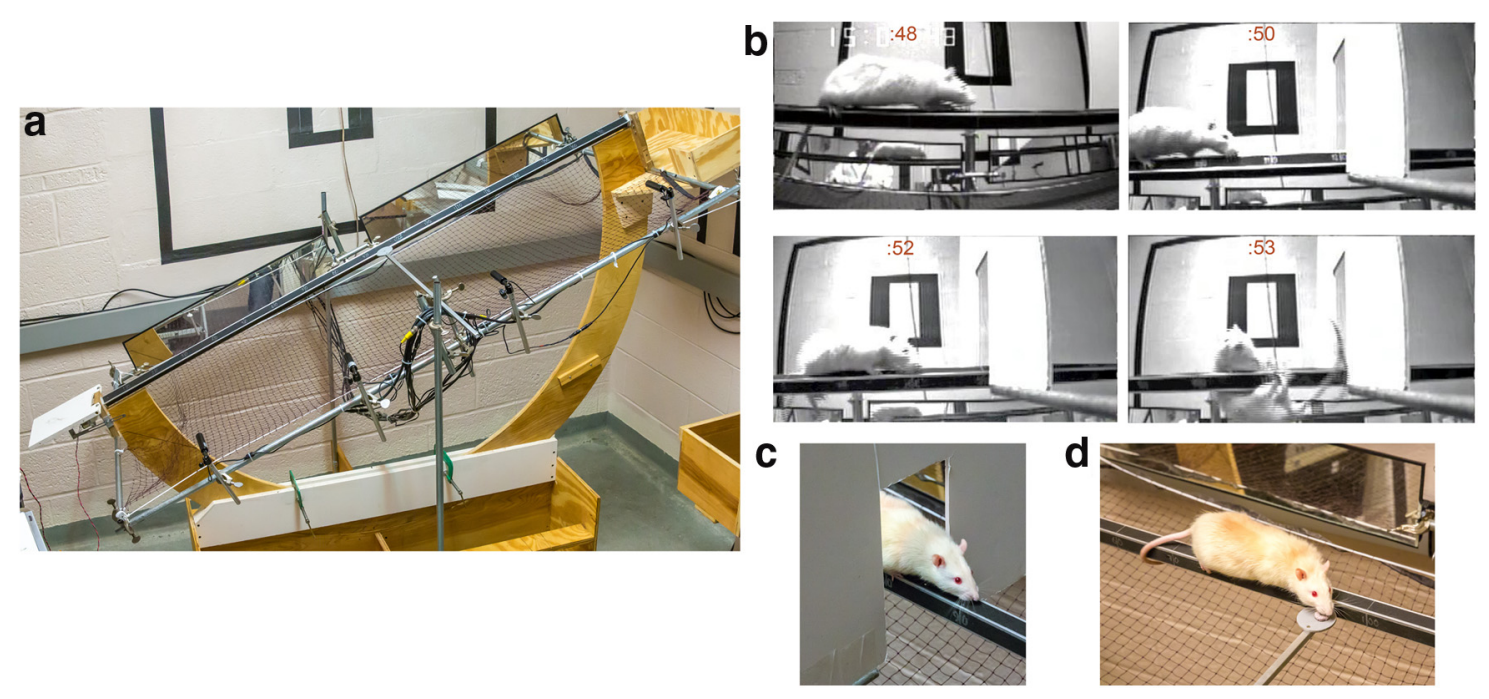

Figure 1. The test apparatus (MCMCT) consists of various runways (plank, round, and square rods, placed horizontally or, as shown in $\boldsymbol{a}$, at inclines), and with rods rotating (10 rpm) while distractors were presented. Cameras and mirrors generate a complete record of each trial. $\boldsymbol{b}$, Rat with cortical cholinergic and striatal dopaminergic deafferentation (DL) traversing a rotating, square rod (note alternating rod surfaces across the 4 shots taken over $5 \mathrm{~s}$; time in seconds indicated on top of each frame). Attentional distraction was triggered by the door frame and caused a fall of this rat (into a net). Control animals exhibit a brief orientation response but rapidly recover control of movement and thus avoid falling (c). $\boldsymbol{d}$, Control rat retrieving an FL while traversing a rotating rod.

distance between the center of the start platform and the home cage was $2 \mathrm{~m}$. To travel from the start platform to the home cage, the apparatus accommodates interchangeable beam elements $1.8 \mathrm{~m}$ in length. For the present experiment, we used a flat plank $13.3 \mathrm{~cm}$ wide and a $2.54 \mathrm{~cm}^{2}$ square-shaped rod. The ends of the beams are held in sockets that allow the beams to be rotated by a gear motor (Cramer, 800 series, 10 RPM) coupled to one end of the beam element. A pulse frequency modulator allows adjustment of the rotational speed. The lower central section of the $\mathrm{U}$ frame is held in a support saddle that allows the upper section to pivot and incline the beam elements. This allows the traversal beams to be adjusted to any angle from $0^{\circ}$ to $45^{\circ}$. Hand clamps secured the rig at the intended angle. The start platform was hinged and could be adjusted to accommodate the incline angle. The upper ends of the U-shaped frame also supported a rectangular frame for securing a safety net $(0.7 \times 0.2 \mathrm{~m})$ section of a badminton net (generic), placed $20 \mathrm{~cm}$ below the beam element. The net frame also serves as a mounting point for the various cameras, mirrors, and distractor elements described below.

Four cameras (KT\&C; model KPCS190SH Black/White Bullet Camera with 1/3" SONY Super HAD CCD; resolution 600 TVL; scanning frequency $15.734 \mathrm{kHz}(\mathrm{H}), 59.94 \mathrm{~Hz}(\mathrm{~V})$; pixels $795(\mathrm{H}) \times 596(\mathrm{~V})$, power DC12 V ( $\pm 10 \%)$, maximal $80 \mathrm{~mA})$ with rotatable bases were fastened to the outer support frame of the outer side of the apparatus by hand clamps. The four cameras were aligned in parallel, clamped $\sim 50 \mathrm{~cm}$ apart, and adjusted so that the entire length of the beam (including the start platform and edge of the home cages) was filmed. The images were relayed to four grids by a splitter (Panasonic; WJ-420 Quad Unit; 120 $\mathrm{V} / 60 \mathrm{~Hz}$ ) displayed on a monitor (Panasonic CT-51390). The monitor was able to display the images from all four cameras simultaneously and also zoom on images captured from each individual camera. The traversals were recorded using a DVD-R (DR430; Toshiba) and Verbatim DataLifePlus DVRs, and the recordings were converted to MPEG-4 Part 14 (mp4) using HandBrake software (free open source; version 0.9.8). Two rectangular-shaped mirrors $(78.0 \mathrm{~cm} \times 15.5 \mathrm{~cm})$ separated by $\sim 20$ $\mathrm{cm}$ were fastened by hand clamps to the side of the apparatus opposite of the cameras to allow for visualization of the animals' movements on the side of the apparatus opposite to the cameras. All trials were recorded for further detailed analyses of performance measures.

Distracting devices were fastened into place by hand clamps connecting to the support frames on either side of the apparatus and could be presented at any distance along the beams (Fig. 1). The door frame distractor surface was $46.0 \mathrm{~cm} \times 39.4 \mathrm{~cm}$ (with a door frame-shaped cutout of $20.0 \mathrm{~cm} \times 10.0 \mathrm{~cm}$ ) made of foam core. The door frame distractor was placed at the $100 \mathrm{~cm}$ mark of the rod with the side jambs $3.5 \mathrm{~cm}$ from the rod surface on either side and the top border of the door frame cutout $11.0 \mathrm{~cm}$ above the flat rod surface. For the Froot Loops (FL) retrieval distractor, the cereal was placed on a platform $(4.9 \mathrm{~cm}$ diameter $)$ that was presented at the $100 \mathrm{~cm}$ mark, with $2-3 \mathrm{~cm}$ separating the rod and the platform (Fig. 1; see below for justification of distractors).

General testing procedure. Rats were brought to the testing room inside of their individual home cages. Typically, 3-6 trials (detailed below) were conducted on each rat during a session, depending on the type of trials. At the start of a session, the lid of the rats' home cage was removed and the cage (containing the rat) was placed inside the holder at the end of the apparatus and given an FL (Kellogg's; $1.8 \mathrm{~cm}$ in diameter, $6 \mathrm{~mm}$ height, $\sim 230 \mathrm{mg}$ ). Subsequent runs were rewarded by delivering an FL to the rat upon returning to the home cage. During initial shaping trials, the rat was placed directly on the plank or rod with their hindpaws situated on the intended interval mark. The experimenter released rats when all four paws were placed firmly to the beams' surface and the animal had attained an upright and symmetrical body positioning. Subsequently, rats were placed on the start platform facing the direction of traversal. Rats were given a maximum of $60 \mathrm{~s}$ to initiate traversal. Falls and other performance measures were only scored after the rat initiated independent forward movement on the rod with the hindpaws situated at the $5 \mathrm{~cm}$ interval mark or beyond. A complete traversal was considered when the rats traveled to within $5 \mathrm{~cm}$ of the home cage at the end of the plank or rod (measured from the front of the rat), at which point the rats' hindpaws were typically located at the $160 \mathrm{~cm}$ interval mark. Thus, performance measures were extracted only during traversal of the first $160 \mathrm{~cm}$ of the beam.

Prelesion practice and test sequence. Rats were first required to complete a series of shaping and test trials using the plank surface. This beam allowed the animals to become acclimated to the traversal procedure. Initially, rats learned to traverse the plank at $0^{\circ}$ incline. After completion of the third traversal, the plank was adjusted to a $22.5^{\circ}$ incline and rats again were required to complete three traversals. Upon completion of the plank trials, a second shaping sequence was performed using the stationary (nonrotating) square-shaped rod. Rats were given as many attempts as necessary to complete a first rod run after being released from the 150 $\mathrm{cm}$ mark. When a fall occurred, the rat was placed into its home cage for $60 \mathrm{~s}$ before the trial was reinitiated. Shaping was considered complete after a rat successfully completed one trial from the $150 \mathrm{~cm}$ mark followed by one successful traversal from the $90 \mathrm{~cm}$ mark in three attempts. For subsequent trials, rats were placed on the start platform and required to complete three full traversals (stationary rod; $0^{\circ}$ incline). After three complete traversals from the start platform in a condition, practice of the 
Table 3. Stationary and rotating rod performance: synopsis of ANOVA results and multiple comparisons

\begin{tabular}{|c|c|c|c|c|c|c|}
\hline & \multicolumn{2}{|l|}{ Traversal time } & \multicolumn{2}{|l|}{ Slips } & \multicolumn{2}{|l|}{ Falls } \\
\hline & $0 \mathrm{rpm}$ & 10 rpm cw & $0 \mathrm{rpm}$ & 10 rpm cw & $0 \mathrm{rpm}$ & 10 rpm cw \\
\hline Group & $* * *$ & $* *$ & $* *$ & $* * *$ & NS & $* * *$ \\
\hline \multirow[t]{2}{*}{ Incline } & $* * *$ & $* * *$ & * & * & $* * *$ & $* *$ \\
\hline & $\begin{array}{l}\text { Slower at } 35^{\circ} \text { than } 0^{\circ} \\
\text { and } 22.5^{\circ}\end{array}$ & $\begin{array}{l}\text { Slower at } 35^{\circ} \text { than } 0^{\circ} \\
\text { and } 22.5^{\circ}\end{array}$ & $\begin{array}{l}\text { More slips at } 35^{\circ} \text { than } 0^{\circ} \\
\text { and } 22.5^{\circ}\end{array}$ & $\begin{array}{l}\text { Fewer slips at } 22.5^{\circ} \text { than } 0^{\circ} \\
\text { and } 35^{\circ}\end{array}$ & $\begin{array}{l}\text { More falls at } 0^{\circ} \text { than } 22.5^{\circ} \text { and } 35^{\circ} \text {; } \\
\text { more falls at } 22.5^{\circ} \text { than } 35^{\circ}\end{array}$ & $\begin{array}{l}\text { More falls at } 0^{\circ} \text { than } 22.5^{\circ} \\
\text { and } 35^{\circ}\end{array}$ \\
\hline
\end{tabular}

NS, Not significant.

${ }^{*} p<0.05 ;{ }^{* *} p<0.01$; ${ }^{* * *} p<0.001$ (mixed-model ANOVAs).

next condition in the sequence was initiated. The conditions were as follows: stationary $\operatorname{rod} / 0^{\circ}$ incline, stationary $\operatorname{rod} / 22.5^{\circ}$ incline, counterclockwise rotating rod $(10 \mathrm{rpm}) / 0^{\circ}$ incline, and $22.5^{\circ}$ incline. Rats were given as many trials as necessary to successfully complete all conditions (three completed runs). The ladder walking task (further described below) was tested as a component of the MCMCT. The rats underwent three ladder trials following completion of the rod traversals. Rats were given a maximum of five trials each day and tested for 2 consecutive days followed by $1 \mathrm{~d}$ of no testing. All animals in the study completed the prelesion sequence within 8 test days.

Postlesion test sequence and distractor conditions. The objective of the postlesion MCMCT test battery was to provide a progressively more demanding sequence of conditions and to tax demands on attentional control of gait, balance, and complex movement (Table 2).

Rats were tested between 4 and $6 \mathrm{~d}$ per week. Animals completed the entire sequence within $35 \mathrm{~d}$. Unlike during prelesion MCMCT testing, consecutive falls did not result in reacclimation trials. Rats were advanced to the next condition (Table 2 ) regardless of performance on the previous condition. The postlesion MCMCT testing sequence included a number of conditions that the rats had not previously encountered in prelesion testing, including consecutive trials during which the rotation direction was alternated (Table 2, counterclockwise-clockwise) and, importantly, the door frame distractor and the FL retrieval task.

The door frame distractor was adopted based on findings that such a distractor slows and freezes movement in PD patients (Cowie et al., 2012). Pilot experiments indicated that the efficacy of this distractor decreases upon multiple exposures; thus, it was presented only during the postlesion testing. To assess the impact of a more efficacious distractor on MCMCT performance, we introduced the FL retrieval task. Retrieving an FL while traversing a rotating rod was thought to introduce a "secondary task," which diverts attention from the primary task of traversing the rod. Such dual-task conditions have been demonstrated to cause movement errors and falls in older adults (Hall et al., 2011; O'Halloran et al., 2011) and PD patients (LaPointe et al., 2010; Yarnall et al., 2011).

To habituate rats to retrieving an FL during traversal, they first underwent $2 \mathrm{~d}$ of shaping, during which rats were offered FL on the right side, at the $\sim 100 \mathrm{~cm}$ mark, and while traversing the stationary rod (day 12) and the counterclockwise rotating rod (day 13). If a rat did not retrieve the FL when first presented the experimenter continued to offer it as the rat began its dismount into the cage. During the actual test trials on the effects of this distractor, the FL were placed on a circular platform mounted to the support frame and presented $\sim 1.5 \mathrm{~cm}$ to the side of the surface of the rod (Fig. 1d). FL were placed on the left or right side of the $\operatorname{rod}($ Table 2).

Measures of MCMCT performance. The primary measures of MCMCT performance were traversal time, slips, and falls, all extracted from trials on rods (Table 3). For trials using the plank, only traversal time was measured. Within each test trial, quantification of these measures began after the rat achieved an upright, stable body posture and initiated for- ward movement. Behavior near the very end of the beam (within $5 \mathrm{~cm}$ from the end and while rat returned to the home cage) was not included. For trials ending with a fall, traversal time and slips were quantified for the performance before the fall and prorated by multiplying the ratio of the distance of a full traversal to the distance where the hind limbs lost contact of the rod during the fall.

Traversal time was defined as the latency to traverse the beam, from the point when the rat first initiated independent forward movement until the limbs of rats reached the $160 \mathrm{~cm}$ mark. When a fall occurred, traversal time was counted up to the point where the rat first ceased forward momentum leading to the fall and then prorated for the entire length of the beam. A slip was scored when any of the rats' paws lost contact with the surface of the rod and extended below the lower horizontal border of the rod during traversal. Slips were counted individually for each paw (hind and front limbs) regardless of the extent of each slip. After a slip of an individual paw, the paw that slipped needed to be repositioned securely on the rod before another slip was counted from the same paw. When a fall occurred, two slips were always counted (one for each hindlimb) in addition to any front limb slips that may have occurred shortly before the fall. If during a fall a rat hung from the rod by both front paws, only two slips were counted (one for each hindpaw).

A fall was scored in the following instances: when both of the rats' hind limbs lost contact with the rod, causing a rat to either dismount into the netting below the rod or hang from the rod by its front paws, when a rat ceased forward momentum and adhered to ("hugged") the rod while it rotated (thus rotating upside down with it), or when an animal stopped forward traversal and perched its body perpendicularly on the rod for $>2$ s. When a fall occurred, the trial was immediately ended and the rat was placed back into its home cage for at least $60 \mathrm{~s}$ before the subsequent trial commenced. Falls were not counted if a rat fell from the starting platform or stepped off the platform and fell before establishing an upright posture on the rod (in this case, the experimenter assisted the rat in beginning traversal).

Performance during trials involving the FL retrieval distractor was scored by counting the number of falls and successful retrievals and by recording the time to traverse. The traversal times in these trials were compared with the traversal times of the same animal during their most recent performances on the rod in the absence of this distractor (day 15 on Table 2) to determine distractor-induced changes in traversal time.

Ladder task. We adopted the ladder rung walking test and the scoring scheme (Metz and Whishaw, 2009) as a control task. Because of our focus on attention-dependent movement control and falls, this task allowed us to test the potential contributions of impairments in place-object working memory. Rats are "front-wheelers" (Schallert and Woodlee, 2005), meaning that hindlimb movement is informed by forelimb movement and vibrissae-based information. Hindlimb slips may indicate impaired transfer of information about rung gaps to circuitry controlling hindlimb movement (Whishaw et al., 2009).

Apparatus. The apparatus consists of a runway $1 \mathrm{~m}$ in length and $7 \mathrm{~cm}$ in width with Plexiglas walls $20 \mathrm{~cm}$ in height. The floor is made of $3-\mathrm{mm}-$ 
diameter rungs that are interchangeable to allow for a variable inter-rung distance $(1-5 \mathrm{~cm})$. The ladder has removable pegs at the start point and end point that allow the ladder to be tilted left or right at angles up to $35^{\circ}$. In the current study, a $0^{\circ}$ incline was used in all trials. The home cage of the animals fits into a holder at the end of the apparatus. The starting platform has dimensions $(24.3 \times 19.0 \mathrm{~cm})$. The ladder rests $0.7 \mathrm{~m}$ above the ground. Four cameras (KT\&C; model KPC-EX20B Black/White Bullet Camera; resolution 420 TVL; scanning frequency $15.734 \mathrm{kHz}(\mathrm{H})$, $59.94 \mathrm{~Hz}(\mathrm{~V}) ; 37(\mathrm{H}) \times 505(\mathrm{~V})$, power DC12 V ( $\pm 10 \%)$, maximum 100 $\mathrm{mA}$ ) were adhered to a metal rod that extended underneath the ladder rungs to film the movement and paw placements of the rats.

Trial procedure. The purpose of the ladder task was to assess traversal speed, immobility, and step misplacements as the rats traversed on irregularly placed ladder rungs. Similar to the MCMCT, rats were trained to leave a start platform, traverse the length of the ladder apparatus, and climb into to their home cages placed inside of a holder at the opposite end of the apparatus. The ladder rungs were inserted so that the distances between successive rungs were irregular (inter-rung distances ranged from 1 to $5 \mathrm{~cm}$ ). Rungs remained in the same pattern for all rats throughout the experiment. Rats were placed on the ladder start platform with the head placed within the vertical Plexiglas walls that surrounded both sides of the ladder rungs and with the front paws placed approximately on the second ladder rung. The first trial conducted during postlesion testing was considered a shaping trial and not used for data analysis. Data from five trials postlesion (of six) were used for analysis.

Measures of ladder performance. We recorded traversal time, immobility time, slips, and paw misplacements. Traversal time commenced once both hind limbs of the rats left the start platform and all four paws had established firm contact on the rungs. The time was stopped once both forelimbs left the rungs at the far end of the apparatus and grasped the edges of the wooden cage holder. Recording of traversal time was also stopped when an animal that had already begun a traversal ceased forward movement for at least $0.5 \mathrm{~s}$, at which point immobility time was measured. Individual paw slips or misplacements were counted for every instance that a paw (generally a hindpaw) either completely slipped off a rung or failed to establish contact of a rung as the rat engaged in a forward step. Slips or paw misplacements were counted individually for each paw regardless of the degree of the slip or misplacement. A maximum of one slip was counted for each paw on the same rung. However, a paw that had slipped or was misplaced was not required to reestablish contact on any particular rung in order for another slip or paw misplacement to be scored for the same paw.

Vermicelli handling test. We adopted the vermicelli handling test (Allred et al., 2008; Tennant et al., 2010) as a control test to determine dexterous forepaw function. Rats were tested using raw enriched vermicelli pasta ( $1.18 \mathrm{~mm}$ diameter, $0.11 \mathrm{~g} /$ piece; Spartan $)$. Individual pieces of raw vermicelli pasta were cut into lengths of $7 \mathrm{~cm}$ using a razor blade and marked with an ultrafine tip marker at $1.75 \mathrm{~cm}$ increments to aid in the visualization of the handling of the pasta piece during video analysis.

The testing box was made of clear Plexiglas $(24.0 \mathrm{~cm}$ width $\times 24.0 \mathrm{~cm}$ length $\times 28.0 \mathrm{~cm}$ height) with a floor mirror to aid visualization during analysis. A camera was placed in the front of the chamber, allowing for a parallel recording of the subject during trials. The camera used was a CVC-13OR B/W Weatherproof Bullet Camera (Speco Technologies). A 40-watt lamp directed upward was placed next to the testing chamber to provide enhanced illumination of the testing environment and allow for clear visualization of the subjects' digit movements.

Subjects were given five pieces of vermicelli in their home cages for at least $5 \mathrm{~d}$ before testing to familiarize rats with the testing areas, pasta handling, and taste (Tennant et al., 2010). Additionally, subjects were habituated to the testing conditions to become acclimated to eating in the test chamber during recording. Data were collected from two test sessions/d, each one consisting of five trials. Of the 10 test trials conducted over $2 \mathrm{~d}$, only trials that allowed for clear visualization of the forepaws were used for analysis. Between three and five trials were analyzed for all rats in the study.

Measures of pasta handling performance. Rats typically hold a pasta piece in both paws and move it toward the mouth using a coordinated asymmetrical holding pattern (Allred et al., 2008). This "grasp" limb is normally placed in a lower position from the mouth than the other paw, to fully grasp the pasta and push. The other paw is referred to as the "guide" paw, which is typically held closer to the mouth than the grasp paw and pushed the pasta toward the mouth with one or two digits and the thumb nub rather than the entire paw. As the rat eats the pasta piece, the paws slowly come together with the piece becoming more perpendicular to the mouth and one paw placed directly above the other, eventually resulting in an interposing of the digits (Allred et al., 2008). We recorded time needed for consumption, length of pauses, forepaw adjustments, drops, and atypical handling behavior. Forepaw adjustments were defined as any visible release or regrasp of the pasta piece or reformation of the paw hold on the pasta piece using extension-flexion and/or abduction-adduction of the digits (Allred et al., 2008). An atypical behavior was considered in the following instances: (1) when paws were held together in a symmetrical fashion while the pasta piece was $3.5 \mathrm{~cm}$ in length or greater; (2) when there was a change in the roles of the "grasp" and "guide" paws after eating had commenced; (3) when the mouth was used to pull the piece through the paws; (4) when there was a failure of the paws to be placed in the typical symmetrical holding pattern before the pasta piece was completely consumed; and (5) when the pasta piece was held in the mouth at an extreme angle while tilting the head (Allred et al., 2008).

Video-based scoring of performance. Performance measures for the three tasks were extracted from video analysis. Video playback was slowed down to $50 \%$ real time or frame-by-frame as needed, and zooming features allowed detailed analysis of body positioning and paw placements. The mirrors on the opposite side of the beams allowed for analysis of both sides of the plank and rods. Several trained undergraduate students blind to the lesion status of the rats conducted video analyses.

Surgery and lesions. Justification of lesions. (1) Limited cholinergic deafferentation (SAP). AChE-PET imaging indicated that, in PD patients, moderate decreases in cortical and thalamic cholinergic terminal integrity were significantly correlated with attentional and other cognitive impairments, and importantly, increased fall propensity (Bohnen et al., 2009; Bohnen and Albin, 2011). PET measures of AChE likely underestimate the loss of cholinergic terminals, as indicated by decreases in ChAT, but not AChE, in the same cortical tissues of patients with Alzheimer's disease (Ikonomovic et al., 2005), and the finding that cholinergic functions are only mildly affected in mice with a heterozygous deletion of the AChE gene (Mohr et al., 2013). Postmortem measures of ChAT activity in the cortex of PD patients indicated a 50-60\% decrease (Mattila et al., 2001). In rats, a minimum loss of $40-60 \%$ of cholinergic inputs to the anterior half of the cortex is required to produce significant impairments in SAT performance (McGaughy et al., 1996; McGaughy and Sarter, 1998; Burk et al., 2002). (2) Limited dopaminergic deafferentation (6-OHDA). A main goal of this experiment was to model the synergistic deficits that result from DA and non-DA circuit dysfunction, causing movement control deficits and increased fall propensity. It was not the goal of this research to model the primary motor symptoms of PD that result from extensive midbrain dopaminergic cell loss. Indeed, the presence of such motor deficits after large dopamine lesions would severely confound the ability to study complex movement control and fall propensity as a separate cluster of symptoms. Therefore, removal of dopaminergic projections was restricted to the dorsal striatum, as such lesions were previously demonstrated to disrupt habitual actions (Graybiel, 2008; for review, see Redgrave et al., 2010) and to contribute to early cognitive impairments in PD (Sawamoto et al., 2008). Moreover, as we wished to test the significance of cholinergic prefrontal dopaminergic striatal interactions, we targeted the medial prefrontal projection field of the prelimbic cortex (Mailly et al., 2013). Despite the limitations of the 6-OHDA lesion model to reproduce the neuropathological process and other neuronal hallmarks of PD, this model remains highly useful for studying the specific hypothesis that dorsal-striatal dopamine loss interacts with cortical cholinergic deafferentation to produce attentional impairments and the associated increase in fall propensity, as well as for the preclinical evaluation of treatments for these symptoms (Beal, 2010). (3) Dual cholinergic-dopaminergic lesions (DL). As a result of cortical cholinergic and striatal dopaminergic deafferentation, attentional control mechanisms were hypothesized to no longer be available for compensat- 
ing for poor habitual control, yielding impaired complex movement control and increased fall propensity.

Methods. Surgeries were conducted in rats that reached criterion performance on SAT (defined above) and successfully completed the MCMCT prelesion training sequence. Surgeries were performed under aseptic conditions. The animals were first placed in vaporization chambers and anesthetized with $4-5 \%$ isoflurane (delivered at $0.6 \mathrm{~L} / \mathrm{min}_{2}$ ) using a SurgiVet Isotec 4 Anesthesia Vaporizer. The animals were then mounted to a stereotaxic instrument (David Kopf Instruments). Isoflurane was maintained at $1-3 \%$ for the remainder of the procedure. The animals' temperature was maintained at $37^{\circ} \mathrm{C}$ using Deltaphase isothermal pads (Braintree Scientific). Rats were given an intraperitoneal injection of an antibiotic (amikacin; $100 \mathrm{mg} / \mathrm{kg}$ ). Ophthalmic ointment was provided for lubrication of the eyes. To prevent hypovolemia and hemodynamic instability during prolonged surgeries, $1 \mathrm{ml} / 100 \mathrm{~g} 0.9 \%$ of $\mathrm{NaCl}$ (s.c.) was administered to the animals. Animals also received an injection of an analgesic (buprenorphine; $0.01 \mathrm{mg} / \mathrm{kg}$; s.c) during surgery and repeated injections once daily beginning the day after surgery. Except for SAP lesions, rats were also injected with desipramine hydrochloride (10 $\mathrm{mg} / \mathrm{kg}$; i.p.; Sigma-Aldrich) $30 \mathrm{~min}$ before the surgery for protection of noradrenergic neurons (Breese and Traylor, 1971). Bilateral infusions were made using a 30 gauge needle attached to a $1 \mu \mathrm{l}$ Hamilton syringe. The cholinotoxic immunotoxin 192 IgG-saporin (SAP; Advanced Targeting System) was suspended in aCSF. The toxin (or aCSF in shams) was infused bilaterally ( $200 \mathrm{ng} / \mu \mathrm{l} ; 0.8 \mu \mathrm{l} /$ hemisphere) into the region of the nucleus basalis and substantia innominata of the basal forebrain (relative to bregma: anteroposterior, $-0.5 \mathrm{~mm}$; mediolateral, $\pm 2.9 \mathrm{~mm}$; dorsoventral, $-7.5 \mathrm{~mm}$ from skull). 6-OHDA (Sigma-Aldrich; $4.0 \mu \mathrm{g} / \mu \mathrm{l} ; 1$ $\mu \mathrm{l} /$ hemisphere) was dissolved in $0.9 \% \mathrm{NaCl}$ with $0.01 \%$ ascorbic acid and infused bilaterally into two sites of caudate nucleus (anteroposterior, $+1.7 \mathrm{~mm}$; mediolateral, $\pm 2.8 \mathrm{~mm}$; dorsoventral, $-5.0 \mathrm{~mm}$; and anteroposterior, $+0.6 \mathrm{~mm}$; mediolateral, $\pm 3.5 \mathrm{~mm}$; dorsoventral, $-5.0 \mathrm{~mm}$ from skull). Infusions were intended to primarily deplete dopamine in the region innervated by prelimbic cortical efferents (Mailly et al., 2013). For dual (DL) lesions and sham surgeries, rats received three infusions per hemisphere. The needle was left in position for 5-10 min to foster absorption of the toxins. Nonabsorbable sutures were used to close the incision and a topical antibiotic (Neosporin) was applied to the wound.

Histology. After completion of the experiments, animals were deeply anesthetized and transcardially perfused with phosphate buffer solution followed by $4 \%$ paraformaldehyde in $0.15 \mathrm{M} \mathrm{Na}$-phosphate buffer with $15 \%$ picric acid, $\mathrm{pH} 7.4$. Brains were removed and postfixed for $2-6 \mathrm{~h}$ at $4^{\circ} \mathrm{C}$, and then rinsed in $0.1 \mathrm{M}$ PBS and stored in $10 \%$ sucrose PBS solution overnight, followed by $30 \%$ sucrose PBS solution the following day and allowed to sink. Coronal sections $(40 \mu \mathrm{m})$ were sliced using a freezing microtome (CM 2000R; Leica) and stored in 0.1 M PBS or antifreeze solution until additional processing. The sections were mounted onto gelatin-coated glass slides and allowed to dry completely. Parallel sections were processed for the immunohistochemical visualization of ChAT or striatal TH-immunostained sections. An orbital shaker was used throughout incubation and rinse periods. For both types of stains, omission of the primary antibody resulted in no specific staining demonstrating substrate specificity for these protocols.

ChAT immunostaining. ChAT immunostaining was accomplished using a Vectastain Elite ABC kit (PK-6105; Vector Laboratories) and a primary antibody (polyclonal goat anti-ChAT; Millipore). Sections were first rinsed three times for 5 min each in $0.1 \mathrm{~m}$ phosphate buffer, $\mathrm{pH} 7.4$, and then incubated in $0.3 \%$ peroxide for $30 \mathrm{~min}$. They were rinsed again in $0.1 \mathrm{M}$ phosphate buffer two times for $5 \mathrm{~min}$ each. After rinsing, sections were incubated for $1 \mathrm{~h}$ in a $1.5 \%$ normal blocking serum with $0.2 \%$ Triton X. After blocking, tissue was immediately transferred to incubate in the primary antibody (goat anti-ChAT made in rabbit; 1:250) overnight at $4^{\circ} \mathrm{C}$. The next day, tissue was rinsed three times for $5 \mathrm{~min}$ each in 0.1 M PBS with $0.2 \%$ Triton X. They were then incubated in the biotinylated secondary antibody (biotinylated rabbit anti-goat; 1:200; supplied in the Vectastain Elite ABC kit) for $2 \mathrm{~h}$. After being rinsed three times for 5 min each in $0.2 \%$ Triton $\times$ in $0.1 \mathrm{~m}$ phosphate buffer, the sections were incubated with the avidin-biotin complex (1:25) for $30 \mathrm{~min}$. They were then rinsed three times for $5 \mathrm{~min}$ each in $0.1 \mathrm{~m}$ phosphate buffer and then developed in a peroxidase substrate solution of $0.4 \%$ DAB and $0.19 \%$ nickel (II) chloride in $0.1 \mathrm{~m}$ phosphate buffer. A total of $10 \mu \mathrm{l}$ of $30 \%$ hydrogen peroxide was added immediately before the rinse. Once sections reached a desired color $(\sim 1-5 \mathrm{~min})$, they were rinsed with $0.1 \mathrm{M}$ phosphate buffer three times for $5 \mathrm{~min}$ each. Sections were mounted on gelatin-coated slides and allowed to dry overnight. The following day, slides were dehydrated in an ascending alcohol series (70\%, 90\%, and $100 \%$ ) and defatted in xylene before coverslipping.

TH immunostaining. TH immunostaining was performed using a Vectastain Elite ABC kit (PK-6100; Vector Laboratories; rabbit IgG) and a primary antibody (ab112; Abcam; polyclonal rabbit anti-TH). Sections were first rinsed in $0.1 \mathrm{M}$ phosphate buffer three times for $3 \mathrm{~min}$ each before a $30 \mathrm{~min}$ incubation in $0.3 \%$ peroxide. The sections were rinsed for $3 \mathrm{~min} 3$ times in $0.1 \mathrm{M}$ phosphate buffer with $0.3 \%$ Triton $\mathrm{X}$ and then incubated in a $1.5 \%$ normal goat serum (blocking serum) with $0.3 \%$ Triton $\mathrm{X}$ for $1 \mathrm{~h}$. The sections were then washed three times for $5 \mathrm{M}$ in 0.1 $\mathrm{M}$ phosphate buffer with $0.3 \%$ Triton $\mathrm{X}$ before incubation in primary antibody (rabbit anti-TH made in goat; $1: 1000$ ) overnight at $4^{\circ} \mathrm{C}$. After $\sim 24 \mathrm{~h}$, the sections were rinsed three times ( 3 min each) in $0.1 \mathrm{M}$ PBS with $0.3 \%$ Triton $\mathrm{X}$ and then were incubated in the secondary antibody (biotinylated rabbit anti-goat; 1:200; supplied in the Vectastain Elite ABC kit) for $30 \mathrm{~min}$. After three rinses for $3 \mathrm{~min}$ each in $0.3 \%$ Triton $\mathrm{X}$ in $0.1 \mathrm{M}$ phosphate buffer, the tissue was incubated with the avidin-biotin complex (1:25) (no Triton) for $30 \mathrm{~min}$. The sections were then rinsed three times in $0.1 \mathrm{M}$ phosphate buffer $(3 \mathrm{~min}$ each) and then developed for $\sim 1-5$ min using a Vector Laboratories DAB Peroxidase Substrate Kit (SK-4100). Sections were rinsed in $0.1 \mathrm{M}$ phosphate buffer three times for 3 min each. The sections were mounted and coverslipped the following day using the same procedure as described above.

Estimates of residual basal forebrain cholinergic neurons. To determine potential relationships between cholinergic cell loss and measures of performance, a semiquantitative estimate of the number of cholinergic neurons was generated. Photographs of the ChAT-stained basal forebrain of the two hemispheres were taken at $10 \times$ magnification using a Leica DM400B digital microscope. Cell count estimates were taken from the area of the nucleus basalis of Meynert (nbM) and substantia innominata (SI) within a $680 \mu \mathrm{m} \times 680 \mu \mathrm{m}$ region, and from the horizontal nucleus of the diagnonal band/preoptic area within a $970 \mu \mathrm{m} \times 1340 \mu \mathrm{m}$ region, as shown in Figure 8f. The "count" function Photoshop CS6 was used to quantify the number of ACh cells. This feature also tags each neuron location noticed to prevent double-counts and allow for review by a second counter. These semiquantitative estimates from the two hemispheres were averaged to yield a single estimate per rat.

6-OHDA lesion rating. TH-immunostained sections were used to generate a single score depicting the placement and size of the bilateral lesions. Placement accuracy ratings were based on the degree to which the center of the lesions was in the medial striatal projection region of the medial prefrontal (prelimbic) cortex (adopted from Mailly et al., 2013) (see Fig. 9a). Lesions centered in and largely limited to this region received the highest score (5), whereas lesions that remained lateral from this prefrontal projection region received placement scores of $\leq 3$, with 1 assigned to lesions not affecting the target area. Second, for each hemisphere, the size of the lesions was scored, with lesions $>2.00 \mathrm{~mm}$ (dorsoventral $) \times 0.5 \mathrm{~mm}$ (mediolateral) $\times 0.5 \mathrm{~mm}$ (anteroposterior; maximum extensions), or $0.5 \mathrm{~mm}^{3}$, rated highest (5) and lesions smaller than $0.1 \mathrm{~mm}^{3}$ receiving the lowest score (1). The placement and size scores ( 2 per hemisphere, 4 per brain) were averaged to yield the 6-OHDA lesion score for an individual rat.

Composite lesion score for DL rats. To determine the relationships between the degree of the two lesions in DL rats and measures of performance, a composite score, reflecting the severity of the two lesions, was generated for each individual DL rat. For this purpose, the degree of cholinergic cell loss of two basal forebrain counting areas per hemisphere (see Fig. $8 f$ ) was also rated from 5 to 1 ( 5 : $>90 \%$ cell loss relative to the grand mean from control rats; $4:>80 \% ; 3:>70 \% ; 2:>60 \% ; 1: 30-50 \%$ loss). Thus, a rat exhibiting a near-complete cholinergic lesion as well as large and accurately placed dopaminergic lesions would receive a composite lesion score of $5 \times 5=25$. 
Confocal microscopy. Separate sections were processed for immunofluorescence examination of the effects of cholinergic and dopaminergic lesions using confocal microscopy. Free-floating sections were incubated overnight with 1/3000 diluted rabbit anti-vesicular acetylcholine transporter (VAChT; Synaptic Systems) antibody or with 1:5000 diluted mouse anti-TH (DiaSorin; in PBS containing 0.2\% Triton X-100 and 2\% normal goat serum, $4^{\circ} \mathrm{C}$ ). On the next day, sections were washed and incubated for $30 \mathrm{~min}$ in a 1/1000 dilution of Alexa-488-conjugated antibody against rabbit IgG (Invitrogen) and a 1/500 dilution of CY3conjugated antibody against mouse IgG (Jackson ImmunoResearch Laboratories). Immunofluorescence was visualized by confocal microscopy (LSM 710; Zeiss).

Statistical analyses. Within-subjects repeated-measures ANOVAs and mixed-model ANOVAs were used to determine differences between the lesion groups (sham, 6-OHDA, SAP, or DL) on each behavioral task (for a definition of main factors and designs, see Results). Mixed-model ANOVAs for SAT data tested the main effects and interactions of signal duration (where applicable: 500, 50, and $25 \mathrm{~ms}$ ) and trial block (five 8 min blocks of trials) on percentage hits, percentage correct rejections, SAT score, and percentage omissions. For MCMCT analyses, repeatedmeasures ANOVAs were used to test for main effects and interactions of traversal condition (stationary rod, regular rotating rod, or reverse rotating rod), incline $\left(0^{\circ}, 22.5^{\circ}\right.$, or $\left.35^{\circ}\right)$, rotation (stationary rod or rotating), and direction of rotation (clockwise or counterclockwise) on measures of performance (detailed above). Pearson product-moment correlation coefficients were computed between measures of SAT and MCMCT performance. Post hoc analyses for within-subjects comparisons were performed using $t$ test and the Least Significant Difference (LSD) test. Statistical analyses were performed using SPSS for Windows (version 17.0; SPSS). In cases of violation of the sphericity assumption, HuyhnFeldt-corrected $F$ values, along with uncorrected degrees of freedom, are given. Alpha was set at 0.05 . As detailed in Results, lower $\alpha$ levels are used for individual analyses to account for the separate analysis of dependent performance measures. Exact $p$ values are reported as was recommended previously (Greenwald et al., 1996).

\section{Results}

\section{Prelesion SAT and MCMCT performance}

Prelesion performance was analyzed to verify that performance did not differ between rats scheduled to receive one of the four types of surgery (factor: "group"). Mixed-model ANOVA on the effects of group (between-subject factor), signal duration (within-subject factor), and block of trials (within-subject factor) on SAT scores indicated the absence of a main effect of group $\left(F_{(3,40)}=1.55, p=0.22\right)$. As was expected, performance varied by signal duration $\left(F_{(2,80)}=573.98, p<0.001\right)$. Performance did not differ across block of trials $\left(F_{(4,160)}=1.87, p=0.20\right)$. All interactions involving the factor group were not significant (all $F<1.01$, all $p>0.43$ ). Post hoc comparisons confirmed higher SAT scores for longest signals compared with $50 \mathrm{~ms}$ signals (500 $\mathrm{ms}, 0.66 \pm 0.01 ; 50 \mathrm{~ms}, 0.23 \pm 0.01 ; p<0.001)$ and $25 \mathrm{~ms}$ signals (25 ms, $0.07 \pm 0.01 ; p<0.001)$. Errors of omission remained generally low $(0.60 \pm 0.06 \%)$ and were also not affected by group $\left(F_{(3,40)}=0.39, p=0.76\right)$.

The analysis of prelesion MCMCT performance was based on trials requiring traversal of the rotating (counterclockwise) rod at $0^{\circ}$ and $22.5^{\circ}$ inclines (three trials at each incline). There were no main effects of group on falls, slips, and traversal time (falls, $F_{(3,40)}=0.12, p=0.95$; slips, $F_{(3,40)}=0.64, p=0.59$; traversal time, $\left.F_{(3,40)}=1.43, p=0.25\right)$. Unexpectedly, the steeper incline produced less falls than traversing the rod at $0^{\circ}$ incline (main effect of incline [within-subject factor]: $F_{(1,40)}=17.89, p<0.001$; $\left.0^{\circ}, 17.73 \pm 3.86 \% ; 22.5^{\circ}, 0.75 \pm 0.75 \%\right)$ and less slips $\left(F_{(1,40)}=\right.$ $\left.16.59, p<0.001 ; 0^{\circ}, 2.31 \pm 0.23 ; 22.5^{\circ}, 1.18 \pm 0.13\right)$. Traversal time was not affected by incline $\left(F_{(1,40)}=0.56, p=0.46 ; 4.58 \pm\right.$ $0.14 \mathrm{~s})$. Importantly, the effects of group and incline did not interact on any measure of performance (all $F<0.77$, all $p>$ 0.52 ). Thus, neither SAT nor MCMCT performance differed between rats assigned to the four groups.

\section{Postlesion SAT performance}

SAT score

Mixed-model ANOVA on the effects of group (between-subject factor), signal duration (within-subject factor), and block of trials (within-subject factor) on SAT scores indicated main effects of all three factors (group: $F_{(3,40)}=9.36, p<0.001$; signal duration: $F_{(2,80)}=211.17, p<0.001$; block of trials: $F_{(4,160)}=3.39, p=$ 0.01 ). Multiple comparisons (LSD) between groups (main effect) indicated that both SAP and DL rats performed at lower levels than shams and 6-OHDA rats (LSD, all $p<0.01$ ). SAT scores did not differ between shams and 6-OHDA rats or between SAP and DL rats. The main effect of signal duration was based on all rats scoring more hits to longest signals compared with $50 \mathrm{~ms}$ (SAT scores based on hits to $500 \mathrm{~ms}$ duration: $0.49 \pm 0.03 ; 50 \mathrm{~ms}$ : $0.13 \pm 0.02 ; p<0.001)$ and $25 \mathrm{~ms}$ signals ( $25 \mathrm{~ms}: 0.04 \pm 0.02 ; p<$ $0.001)$. The main effect of blocks of trials reflected a general decline in performance during the last (fifth) and fourth blocks of trials compared with the first block of trials (SAT score for block 1: $0.26 \pm 0.02$; block 5: $0.18 \pm 0.03, p<0.001$; block 4: $0.20 \pm$ $0.03, p=0.02$ ).

The effects of group and signal duration on SAT scores interacted significantly $\left(F_{(6,80)}=5.67 ; p<0.001\right.$; Fig. $\left.2 a\right)$, whereas all other two- and three-way interactions involving group remained insignificant (all $F<1.20$, all $p>0.29$ ). Post hoc analyses of the interaction first indicated significant effects of group separately for each signal duration (all three: $F>5.69, p<0.002$ ). Multiple comparisons (Fig. 2a) indicated mainly that SAT scores calculated over hits to the longest signal duration were lower in SAP and DL rats than in shams and 6-OHDA rats. Unexpectedly, SAT scores for the two shorter signals were higher in 6-OHDA rats than in all other groups. Collectively, the SAT scores from the four groups indicate that cholinergic lesions impaired SAT performance and that additional 6-OHDA lesions (DL) did not augment this impairment.

\section{Hits, correct rejections, omissions}

The significant interaction between the effects of group and signal duration found in the analysis of SAT scores (above) was reproduced in the analysis of hits (group: $F_{(3,40)}=2.06, p=0.12$; duration: $F_{(2,80)}=194.61, p<0.001$; group $\times$ signal duration: $F_{(6,80)}=7.60, p<0.001$; Figure $\left.2 b\right)$. The interaction between group and signal duration was explored by post hoc one-way ANOVAs on the effects of group for hits to individual signal durations. This analysis indicated a significant effect for only hits to longest signals $\left(F_{(3,44)}=4.55, p=0.008\right.$; medium and short durations: both $F<2.58$, both $p>0.06)$. Multiple comparisons found that the hits in DL rats were significantly lower than in sham and 6-OHDA rats (Fig. 2b). The analysis of correct rejections did not indicate the effects of group $\left(F_{(3,40)}=1.82, p=0.16\right.$; Fig. $2 c)$. Finally, omissions remained low and did not differ between groups $\left(F_{(3,40)}=0.75, p=0.53\right.$; Fig. $\left.2 d\right)$.

Thus, together, postlesion SAT performance was characterized by a decrease in hits in animals with loss of cholinergic neurons (SAP and DL). Striatal dopamine loss did not augment the impairment in SAT performance that resulted from cholinergic lesions. These findings also confirm that the integrity of the cortical cholinergic input system is necessary for SAT performance (McGaughy et al., 1996; Howe et al., 2013). 


\section{Postlesion MCMCT performance}

Effects of repeated MCMCT testing

As detailed in Table 2, rats were tested on the MCMCT for 20 consecutive days/sessions, using increasingly complex and presumably progressively demanding conditions (e.g., from stationary rods to rotating rods to alternatingly rotating rods, from horizontal rods to $22.5^{\circ}$ and $35^{\circ}$ inclines, and with the addition of distractors). This sequence was designed to counteract potential performance benefits resulting from repeated testing while reliably revealing the expected performance deficits of animals with lesions. To quantify the impact of repeated testing and to verify the overall efficacy of this design, fall rates from all sessions/conditions using the rotating rod, but not involving the plank, stationary rod, distractor shaping, and distractor tests, were analyzed using a mixed-model ANOVA on the effects of group (betweensubject factor) and condition (withinsubject factor). The main effect of group $\left(F_{(3,40)}=16.12, p<0.001\right)$ reflected that DL rats fell more frequently than all the other three groups and that SAP rats fell more often than shams and 6-OHDA rats (Fig. 3). The main effect of condition also reached significance $\left(F_{(8,320)}=4.56, p<\right.$ 0.001). Multiple comparisons generally indicated lower falls in later when compared with earlier conditions ( 1 vs $2,5,7$, and $8 ; 2$ vs $8 ; 3$ vs $4,5,7$, and $8 ; 4,5,6$, and 7 vs 8 ; all $p<0.05)$. The interactions between the effects of group and condition were not significant $\left(F_{(24,320)}=1.00, p=0.46\right)$, indicating that, although all animals improved their performance with repeated MCMCT testing, DL and SAP rats consistently fell more frequently throughout the testing sequence, presumably reflecting the implementation of progressively more demanding traversal conditions.

\section{Individual test conditions}

Plank traversal. Postlesion plank traversal tests were conducted at $0^{\circ}, 22.5^{\circ}$, and $35^{\circ}$ incline (different inclines were tested on separate days; see Materials and Methods). The analysis of the effects of group (between-subject factor) and incline (within-subject factor) on traversal time yielded a trend for a main effect of group $\left(F_{(3,40)}=2.79, p=0.053\right)$, a main effect of incline $\left(F_{(2,80)}=18.00\right.$, $p<0.001)$, and a significant interaction between the two factors $\left(F_{(6,80)}=3.42, p=0.005\right)$. Post hoc multiple comparisons of the main effect of group indicated that DL rats were significantly slower than the other three groups (all $p<0.03$ ). Furthermore, and as expected, all animals were slower traversing the plank at $22.5^{\circ}$ and $35^{\circ}$ incline compared with $0^{\circ}$ (both $p<0.006$ ), and also slower at the steepest compared with the $22.5^{\circ}$ incline ( $p=0.003$; Fig. 4a). Post hoc one-way ANOVAs over the effects of group per incline level indicated a significant effect for the $35^{\circ}$ incline $\left(F_{(3,43)}=4.95, p=0.005\right)$. DL rats were slower than all other groups at the $35^{\circ}$ incline (all $p<0.01$; Fig. $4 a$ ).

Stationary and rotating rods. All remaining MCMCT tests were based on rod beam performance. Distractor conditions (door frame and FL retrieval) were interspersed within these trials and analyzed separately (below). We first determined the rats' ability to traverse the stationary (nonrotating rod) at the three inclines. Table 3 and Figure 4 provide an overview over main findings from ANOVAs and illustrate main results, respectively. This section will summarize, and where possible condenses, the main findings, focusing on results that, given the analysis of three dependent measures (traverse time, slips, and falls), are significant at an $\alpha$ of $0.05 / 3=0.016$. Except for one condition (falls on stationary rod), DL rats performed worse than all other groups (main effect of group: all $F_{(3,40)}>7.04$, all $p<0.001$; Fig. $4 c, f$ ). Multiple comparisons did not indicate differences between shams, 6-OHDA, and SAP rats. At the steepest incline, animals were generally slower and committed more slips than at $22.5^{\circ}$ or $0^{\circ}$ inclines. Rotating the rod did not worsen the effects of incline (Table 3), and the effects on incline did not interact with group (Table 3).

The analysis of falls from rods at steeper inclines generated unexpected results. Although DL rats produced more falls on the rotating rod than the other three groups (above), all rats generated more falls when traversing the flat rod $\left(0^{\circ}\right.$ incline) compared with steeper inclines (regardless of stationary or rotating; main effects of incline on falls; both $\left.F_{(2,80)}>5.37, p<0.006\right)$. Moreover, on the stationary rod, DL rats fell more often than the other three groups but only at $0^{\circ}$ incline (group $\times$ incline: $F_{(6,80)}=$ $3.17, p=0.008$; Fig. $4 b$ ). Rotating the rod abolished this interaction, with DL rats falling more often than all other rats at all inclines (main effect of group; Table 3; Fig. 4d). In summary, these analyses indicated that DL rats were impaired traversing the 


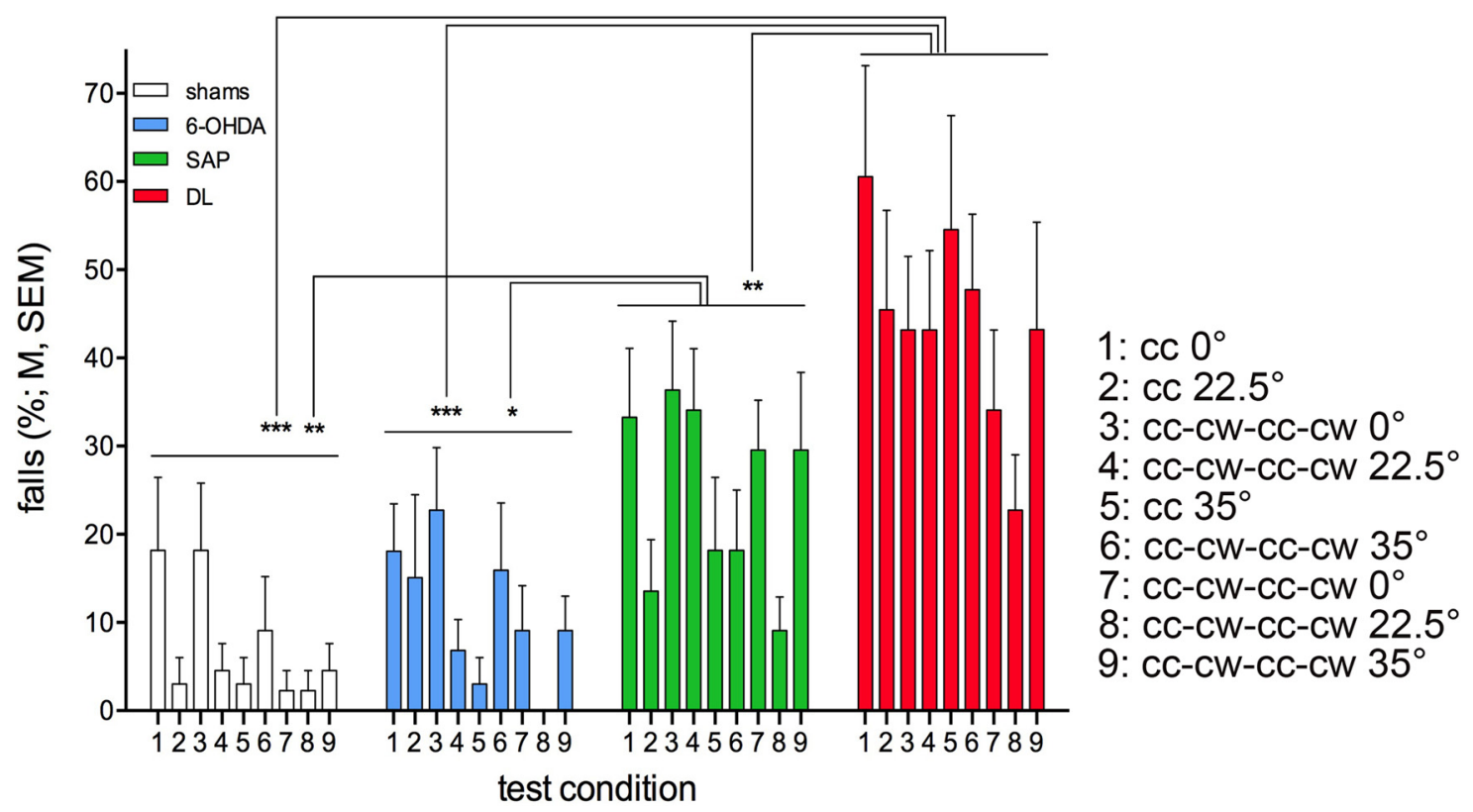

Figure 3. Fall rates across the MCMCT sequence shown in Table 2, except for plank trials, rod shaping, distractor shaping, and distractor trials ( $N=44, n=11$ per group). The distractor trials were designed to generated higher fall rates and thus were not included in this analysis of the effects of repeated testing on the MCMCT. ANOVA (see Results) confirmed that all rats improved across these sessions/conditions but that DL and SAP rats fall consistently more often than 6-OHDA and shams (multiple comparisons indicated).

a

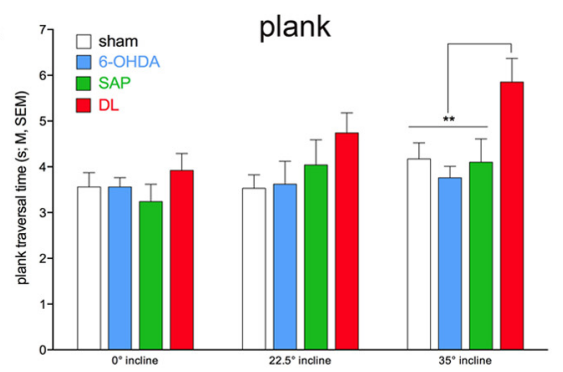

C

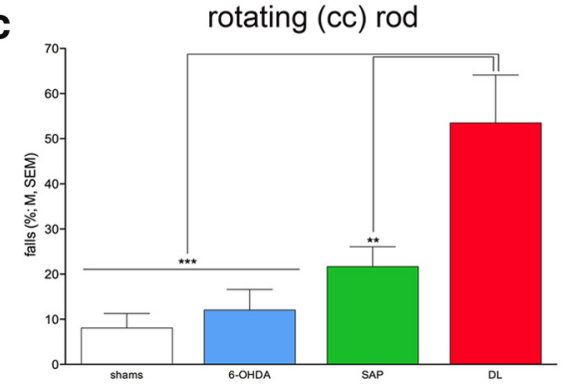

b

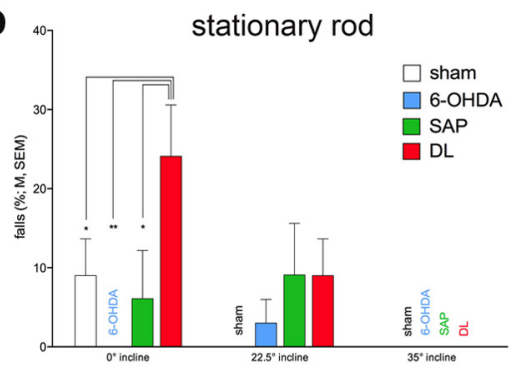

d

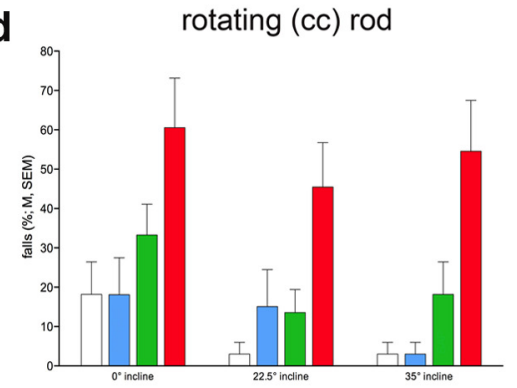

Figure 4. Postlesion MCMCT performance (see also Table $4 ; N=44, n=11$ per group). $\boldsymbol{a}$, DL rats required more time to traverse the plank at $22.5^{\circ}$ and $35^{\circ}$ inclines than the rats of the other three groups (see Results for ANOVAs). $\boldsymbol{b}, \mathrm{DL}$ rats also committed more falls while traversing the stationary rod; unexpectedly, all animals fall less at steeper inclines (group name instead of bar indicates no falls). $\boldsymbol{c}, \boldsymbol{d}$, Rotating the rod counterclockwise again revealed the greater fall propensity of DL rats compared with all other animals (main effect of group in c), but rotating the rod prevented the performance benefits of steeper inclines seen on the stationary rod (because there was no interaction between the effects of group and incline, $\boldsymbol{d}$ does not indicate multiple comparisons).

rod, but even DL rats' performance was relatively better when traversing the stationary rod at steeper inclines.

Reverse rotation effects. Animals were trained traversing the rotating rod using counterclockwise rotation (Table 2). Clockwise rotation rod traversal performance was assessed on selected days as indicated in Table 2. Performing this unfamiliar version of the task was thought to tax traversal performance and thus limit the activation of performance reserves by steeper inclines, thereby revealing more falls in lesioned rats and for steeper inclines. Omnibus ANOVA confirmed that rotation direction affected falls (main effect of rotation direction: $F_{(1,40)}=35.01, p<0.001$; counterclockwise, $9.66 \pm 1.92 \%$ falls; clockwise, $31.63 \pm 3.47 \%$ ). Furthermore, DL as well as SAP rats fell more frequently than shams and 6-OHDA rats (main effect of group: $F_{(3,40)}=12.44, p<0.001$; shams, $6.82 \pm 2.20 \%$ falls; 6-OHDA, $10.61 \pm$ $2.42 \%$; SAP, $26.14 \pm 3.91 \%$; DL, $39.02 \pm$ 4.52\%; multiple comparisons indicated that DL and SAP rats fall more often than shams and 6-OHDA rats, both $p<0.02$ and DL rats also fall more often than SAP rats, $p=0.04)$. Moreover, the effects of group and rotation direction interacted significantly $\left(F_{(3,40)}=4.07, p=0.01\right)$. As illustrated in Figure $5 a$, DL rats fall more often than SAP rats in the counterclockwise condition, but when tested in the rarer clockwise condition, both SAP and DL rats fall in approximately half of these trials. However, contrary to our expectation, steeper inclines again failed to worsen the performance of lesioned rats (no interaction between group, rotation direction, and incline; Fig. 5b).

Distractor-induced falls. Subgroups of PD patients exhibit freezing if presented with passive distractors, such as doorways (Cowie et al., 2012), thereby increasing the risk for gait disturbances, movement errors, and falls (Cole et al., 2010, 2011; Plotnik et al., 2012). Furthermore, distractors that compete more actively for attentional resources, acting as secondary tasks if coinciding with ongoing demands on gait control and complex 
movement (primary task), trigger falls in PD patients (LaPointe et al., 2010; Lord et al., 2010).

The door frame distractor was presented four times, on days 5 (familiarization) and 8 (Table 2), to rats traversing the rotating rod (counterclockwise) at $0^{\circ}$ incline. Performance was analyzed based on falls from three trials on day 4 (no distractor but using identical testing conditions) and on three trials in the presence of the distractor (second trial on day 5 plus two trials on day 8). Because we observed that repeated exposure to this passive distractor lessened its impact, this analysis also included the factor trial (three trials). This analysis confirmed the efficacy of the distractor in triggering falls (main effect: $F_{(1,40)}=7.73, p=0.008$; no door, $32.52 \pm$ $4.85 \%$ falls; door, $53.03 \pm 5.55 \%$ ). Moreover, DL rats fell more frequently compared with all other rats (main effect of group: $F_{(3,40)}=3.32, p=0.029$; shams, $31.82 \pm 8.06 \%$ falls; 6-OHDA, $36.27 \pm$ $8.47 \%$; SAP, $40.86 \pm 6.58 \%$; DL, $62.09 \pm$ 7.39\%; multiple comparisons indicated DL fell more often than shams and 6-OHDA rats; both $p<0.03$ ). Repeated testing (within a daily session) markedly reduced fall frequency (main effect of trial: $F_{(2,80)}=5.00, p=0.009$; trial 1 , $57.97 \pm 5.13 \%$ falls; trial 2, $39.77 \pm$ $5.29 \%$; trial 3, $29.55 \pm 5.22 \%$; more falls in trial 1 than in 2 and 3 ; both $p<0.05$ ), but this improvement did not interact with the effects of groups and distractor (both two-way and one three-way interaction: all $F<0.93$, all $p>0.49$; Fig. $6 a$ ).

The FL was presented during traversal of the rotating rod $\left(0^{\circ}\right.$ incline $)$. The direction of rotation as well as the side of the rod on which the food reward was placed was changed between test days to persistently challenge traversal performance (days 14, 16, 18, and 20; Table 2). To simplify this analysis, the effects of group and distractor were analyzed over averaged fall scores from these $4 \mathrm{~d}$; control data were taken from day 15 (alternating rotation direction, no distractor). This distractor likewise increased the number of falls $\left(F_{(1,40)}=8.09, p=0.007\right.$; no FL, $18.75 \pm 3.55 \%$ falls; FL, $28.91 \pm 3.48 \%)$. Also, as before, a main effect of group $\left(F_{(3,40)}=7.43, p<0.001\right)$ indicated that DL rats fell more often than shams and 6-OHDA rats (both $p<0.001$ ) but, in this case, SAP rats also fell more frequently than shams and 6 -OHDA rats (both $p<0.03$ ). However, mirroring the effects of the door frame distractor, the group $\times$ distractor interaction failed to reach significance $\left(F_{(3,40)}=1.33, p=0.28\right.$; Figure $\left.6 b\right)$.

The absence of a greater impact of the distractor on falls in lesioned rats raised the possibility that, as a result of specifically loss of cortical cholinergic inputs (SAP and DL), the processing of information about the distractor was attenuated, thereby diminishing the impact of the distractor (see the diminished distractor effects in SAP rats in McGaughy et al., 1996). To test this hypoth- esis, we predicted that distractors, presented in trials not leading to falls, slow traversal time less in SAP and DL rats than in the other two groups. Thus, we analyzed traversal time for those trials during which the door frame or FL distractor was presented, which did not end in falls and, regarding the FL distractor, in which the animals did not attempt to retrieve the FL (as falls and retrievals would invalidate traversal time comparisons between trials with and without distractors). The analysis confirmed that presentation of both distractors slowed traversal time (main effects: door frame, $F_{(1,32)}=22.36, p<0.001$; no door, $5.55 \pm$ $0.27 \mathrm{~s}$; door, $6.80 \pm 0.30 \mathrm{~s}$; FL, $F_{(1,37)}=35.54, p<0.001$; no FL, $4.76 \pm 0.28 \mathrm{~s} ; \mathrm{FL}, 5.97 \pm 0.29 \mathrm{~s})$. DL rats were again generally slower, although the main effect of group reached significance only in the analysis of the effects of the door frame distractor $\left(F_{(3,32)}=3.43, p=0.03 ; \mathrm{FL}, F_{(3,37)}=1.94, p=0.14\right)$. Furthermore, the effects of group and distractor on traversal time inter- 

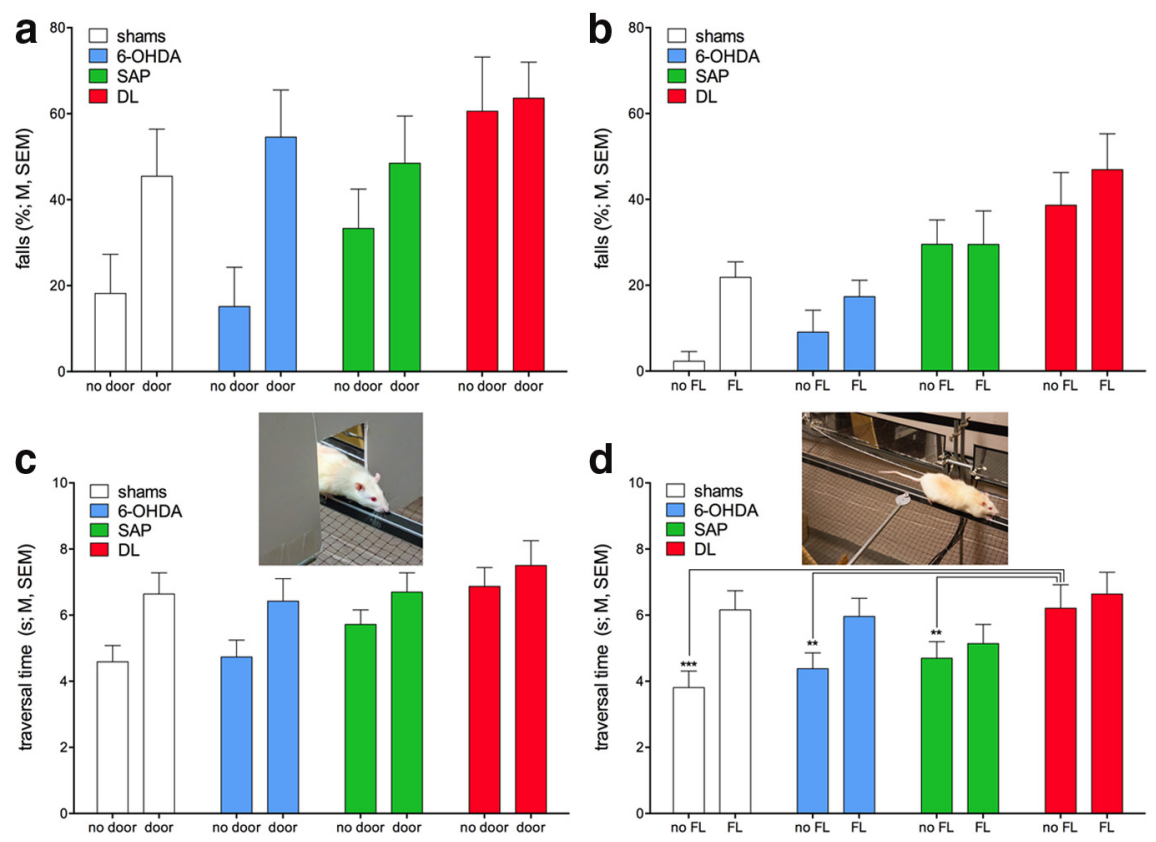

Figure 6. DL rats again generally fell more frequently than all other rats, and the door frame $(\boldsymbol{a})$ as well as the FL $(\boldsymbol{b})$ distractor increased falls in all rats (see Results for main effects; $N=44, n=11$ per group). As we hypothesized that the distractors were less effectively processed in rats with loss of cholinergic neurons (SAP and DL), we also analyzed traversal time in trials in which the distractors did not produce falls and, in case of the FL distractor, did not generate retrieval attempts $(\boldsymbol{c}, \boldsymbol{d})$. Traversal speed slowed in the presence of distractors in shams and 6-OHDA rats, yielding a significant interaction between distactor and group in the analysis of the effects of the DL distractor. $\boldsymbol{d}$, Results of post hoc one-way ANOVAs indicating that shams, 6-0HDA, and SAP rats were faster than DL rats in the absence of the distractor but that distractor-induced slowing of the traversal speed of shams and 6-0HDA rats abolished this difference.

acted significantly for the analysis of the FL distractor $\left(F_{(3,37)}=\right.$ $5.33, p=0.004)$ but not for the door frame distractor $\left(F_{(3,32)}=\right.$ $1.31, p=0.29)$. Inspection of the traversal times for these nonfall/ nonretrieval trials indicated that the presence of the distractor slowed the traversal speed of shams and 6-OHDA rats but not of SAP and DL rats (Fig. $6 c, d$ ). As shown in Figure $6 d$, shams and 6 -OHDA rats required $61 \%$ and $36 \%$ more time to traverse the rod in the presence of the FL distractor, whereas SAP and DL rats added only $9 \%$ and $7 \%$, respectively. Post hoc one-way ANOVAs further indicated that, in the absence of a distractor, DL rats required more time to traverse the rod than all other rats $\left(F_{(3,37)}\right.$ $=4.10, p=0.013)$, whereas in the presence of the distractor this difference was abolished $\left(F_{(3,47)}=1.14, p=0.35\right.$; see Fig. $\left.6 d\right)$.

\section{Microbehavioral analysis of falls in DL rats}

DL rats consistently fell more frequently than the other groups, specifically on the rotating rod. They were also generally slower in traversing rods (and planks) and generated more slips (see further below for correlations between measures of performance). We inspected falls as well as completed runs in DL and sham rats (counterclockwise, $0^{\circ}$ incline) to identify putative overt behavioral correlates associated with slips and falls, and with preventing recovery from slips. Although the speed and resolution of the available recording technique limited this video-based analyses, several salient features were extracted that contributed to the greater fall propensity in DL rats and their more limited ability to recover form slips.

Slower traversal speed, lower step frequency and "slouched posture" in DL rats

As already described, DL rats are generally slower; and as will be described below, traversal speed and falls are significantly corre- lated in DL rats. DL rats traveled less distance per step (sham, $15.97 \pm 0.43 \mathrm{~cm}$ per step; DL, $14.79 \pm 0.30 ; t_{(21)}=4.91, p=$ 0.04 ), and this required more time to complete a stride cycle (sham, $0.41 \pm$ $0.04 \mathrm{~s} ; \mathrm{DL}, 0.56 \pm 0.05 ; t_{(21)}=6.47, p=$ $0.02)$. A relatively lower forward momentum may less effectively counteract the perpendicular (leftward) force exerted by the counterclockwise rotating beam. DL rats often attempted to compensate for this by "overreaching" with their front paws in an attempt to cover more distance per stride; however, relatively slow hindlimb movement often resulted in overextension, lowering of their bodies onto the rod, and thereby hindering hindlimb replacement when slips occurred. This "slouched posture" was also associated with the tail pointing downward and limp (see Less effective rebalancing after slips in DL rats). We quantified the frequency of such postures during the $50 \mathrm{~cm}$ preceding a fall (DL, $68.97 \pm 8.74 \%$ of falls preceded by "slouched posture"; shams, $27.27 \pm$ $\left.14.08 \% ; t_{(39)}=2.28, p=0.02\right)$.

\section{More micropauses in DL rats}

Shams are faster, and they appear to generally exhibit a more fluid run across the rod. An estimate of the number of micropauses, defined as a momentary freezing of forward movement lasting no longer than $1 \mathrm{~s}$, indicated a significantly greater number of such pauses in completed runs in DL rats (shams, $0.64 \pm$ 0.15 micropauses per trial; DL, $1.36 \pm 0.25 ; t_{(21)}=2.91, p=$ $0.02)$. On the rotating rod, micropauses enhance the risk for slips and impose balance corrections, thereby increasing the risk for falls (falls of category 2; see above).

\section{Less effective rebalancing after slips in DL rats}

After a slip on the rotating rod counterclockwise, shams appeared to use active tail motion to assist rebalancing associated with rapid reinitiation of forward movement. In contrast, tail motions in DL rats were often absent, and reinitiation of forward movement was delayed (see also "slouched position," above). We analyzed trials in which slips caused a pause, but not a fall, and counted the proportion of trials in which active tail motion and forward movement immediately followed the slip, as opposed to triggering a prolonged stoppage and a slow recovery (DL, $68.75 \pm$ $11.97 \%$ of trials with slow recovery; shams, $30.77 \pm 13.33 \%$; $\left.t_{(28)}=4.56, p=0.04\right)$. In these cases, DL rats recovered forward movement by a sudden push up from a "slouching position" and in the forward direction.

\section{Correlations between SAT and MCMCT performance}

We hypothesized that the relatively poorer MCMCT performance of SAP and DL rats was associated with poorer SAT performance. Moreover, relationships between MCMCT measures (falls, slips, traversal time) were analyzed. Correlations with SAT performance were calculated using the relative number of hits to $500 \mathrm{~ms}$ signals because "floor" effects in the hits to shorter signals prevent the demonstration of lesion effects. 
The number of falls in the MCMCT (averaged per animals over all rod conditions not involving distractors and shaping conditions) was higher in DL rats that missed more signals in the SAT (hits averaged per rat based on the three sessions that took place during the last $3 \mathrm{~d}$ of MCMCT testing). Such a correlation was not found in the data from the other three groups (Fig. 7a). Notably, inspection of the data in Figure $7 a$ indicates that the hit rates of several SAP rats were as low as for DL rats, yet these rats did not fall as often as DL rats. In contrast, slips and hits were correlated in both SAP and DL rats (Figure $7 b$ ). Together, these observations suggest that increases in slips reflect the (attentional) impact of cholinergic lesions (SAP and DL), but for slips to reliably produce falls, additional striatal dopaminergic damage is required. Falls are also correlated with traversal time, except for 6-OHDA rats (Fig. 7d), and slips and traversal time were positively correlated in all four groups (data not shown; all $R^{2}>$ 0.40 ; all $p<0.05$ ). Thus, lower traversal speed, slips, and falls are interrelated measures of MCMCT performance, but low hit rates in the SAT predicted falls only in DL rats.

\section{Sensorimotor control tests}

As noted in Materials and Methods, the ladder task and the vermicelli pasta handling tests were used to assess potential effects of the lesions on primary sensorimotor skills, specifically hindlimb control and dexterous forepaw function, respec-

tively. DL rats were slower than all the other three groups in traversing the ladder $\left(F_{(3,43)}=5.92, p=0.002\right.$; shams, $6.48 \pm$ $0.40 \mathrm{~s} ; 6-\mathrm{OHDA}, 6.92 \pm 0.33 \mathrm{~s}$; SAP, $6.81 \pm 0.43 \mathrm{~s} ; \mathrm{DL}, 8.50 \pm$ $0.28 \mathrm{~s}$; DL vs all other groups, all three, $p<0.005$ ). However, neither immobility time nor the number of slips differed between groups (both $F_{(3,44)}<2.64$, both $p>0.06$ ).

After completion of the MCMCT sequence, 8 shams and 7 DLs were tested on the vermicelli pasta handling test. Groupbased comparisons of latency to eat, duration of pauses during consumption, number of left and right paw adjustments, drops, and number of atypical consumption behaviors (defined in Materials and Methods) did not yield any significant differences (with $\alpha$ adjusted to $0.05 / 6$ ). Rats required $26.14 \pm 1.74 \mathrm{~s}$ to consume one piece of pasta, paused for a total of $2.23 \pm 0.85 \mathrm{~s}$, made $12.57 \pm 1.82$ right and $11.67 \pm 1.17$ left paw adjustments, dropped the pasta $0.082 \pm 0.035$ times, and exhibited $3.49 \pm 1.23$ atypical consumption behaviors.

\section{Histological analyses}

Generally, SAP lesions resulted in variable levels of cholinergic cell loss (losses ranging from $20 \%$ to $>90 \%$ based on estimates of residual ChAT-positive neurons in the basal forebrain and ChAT- or VAChT-immunoreactive puncta in the cortex; Fig. 8). As previously observed (McGaughy et al., 1996, 1999; Turchi and Sarter, 2000; Burk et al., 2002), SAP diffuses readily and thus
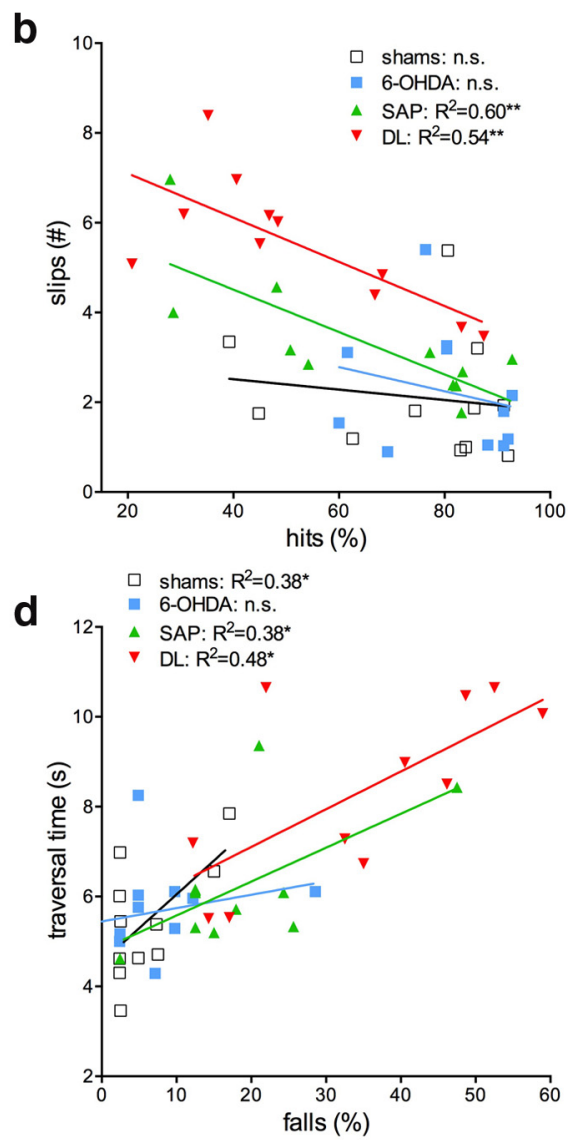

Figure 7. Correlations between SAT performance and falls and slips in the MCMCT $(\boldsymbol{a}, \boldsymbol{b})$ and between measures of MCMCT pefformance $(\boldsymbol{c}, \boldsymbol{d})$; square correlation coefficients for the relationship between the measures and for individual groups are CMCT (a). In contrast, cholinergic cell loss, including in DL rats, appears to be specifically correlated with slips $(\boldsymbol{b})$. Falls are correlated with slips and traversal time in all groups, except 6-0HDA rats $(\boldsymbol{c}, \boldsymbol{d})$, and traversal time and slips were significantly correlated in all groups (data not shown; see Results).

reliably deafferented medial, dorsal, and parietal cortical regions, resulting in minor variations of the lesion space. Semiquantitative estimates of residual ChAT-positive neurons in the two counting regions (Fig. $8 f$ ) were as follows: nbM: shams, $23.13 \pm$ 4.48; SAP, $7.22 \pm 1.40$; DL, $5.72 \pm 1.18 ; F_{(2,25)}=13.14, p<0.001$; post hoc comparisons indicated lower numbers on SAP and DL compared with shams; HDM: shams, $137.38 \pm 15.54$; SAP, $50.44 \pm 8.85 ; \mathrm{DL}, 58.83 \pm 16.28 ; F_{(2,25)}=11.50, p<0.001$; post hoc comparisons indicated lower numbers on SAP and DL compared with shams. The estimates from the two counting regions were significantly correlated (SAP and DL rats; $R^{2}=0.39 ; p=$ 0.0007), reflecting the diffusion of the immunotoxin into the dorsal and ventral counting region. Estimates taken from the dorsal (nbM) but not ventral counting area (HDB; Fig. $8 f$ ) correlated with hits (nbM: $R^{2}=0.24 ; p=0.041$ ), confirming that prefrontal and frontoparietal deafferentation causes SAT impairments (Luiten et al., 1987; McGaughy and Sarter, 1998). Residual cholinergic cell estimates did not correlate with falls (all $R^{2}<0.03$ ).

Infusions of 6-OHDA into the caudate nucleus generated reliable, $>90 \%$ reductions in TH immunoreactivity (Fig. $9 g, h$ ) yet resulted in more variable lesion spaces. Thus, 6-OHDA lesions were scored on the basis of their location (higher scores for placements in the terminal field or medial prefrontal projections; see Fig. 9a) and extension (Fig. 9a-f; see Materials and Methods). 6-OHDA lesion scores ranked from 1 to 5 (best placed and larg- 
a

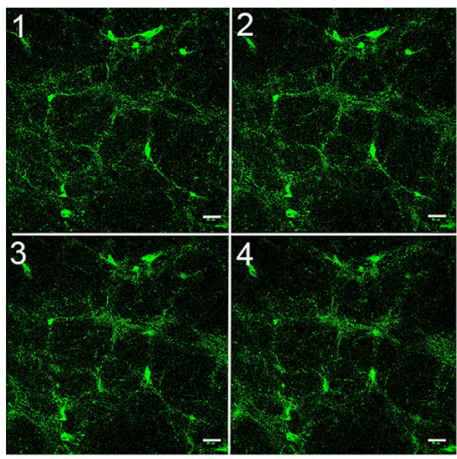

C

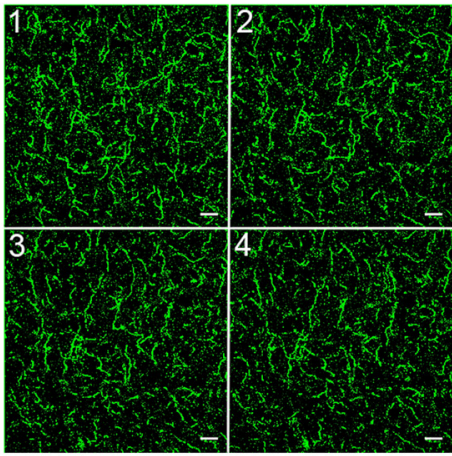

b

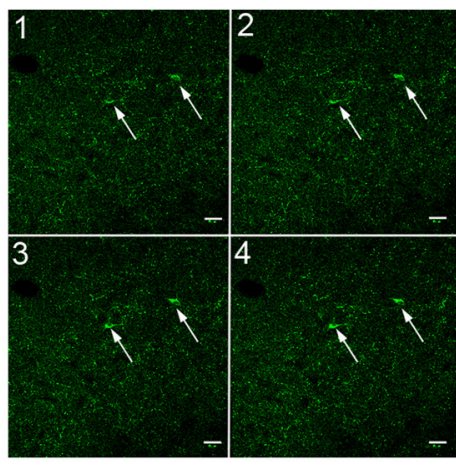

d

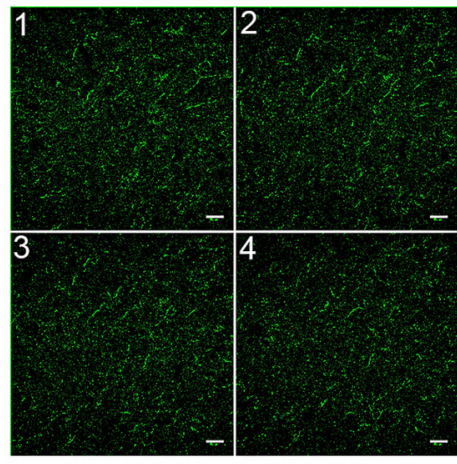

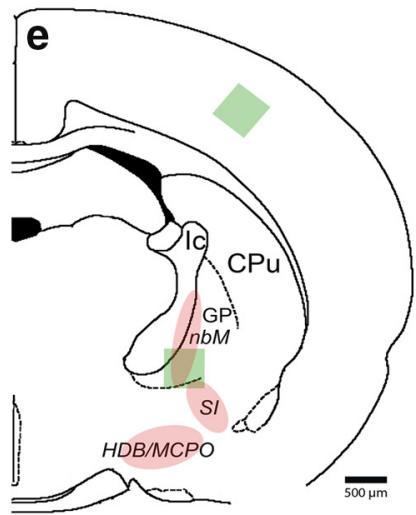

$\mathbf{f}$

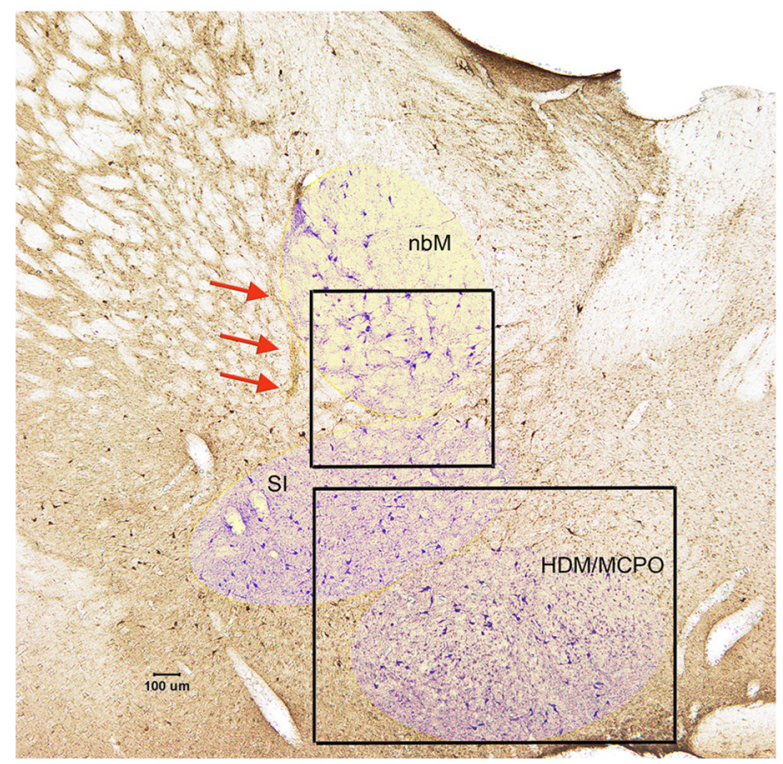

Figure 8. $\boldsymbol{a}, \boldsymbol{b}$, Cholinergic neurons and varicosities, visualized by confocal microscopy (1-4are consecutive slices) of VAChT immunofluorescence, in the intact basal forebrain ( $\boldsymbol{a} ; 20.43 \mu \mathrm{m} / \mathrm{slice})$ and the same region of a SAP-lesioned rat $(\boldsymbol{b} ; 3.77 \mu \mathrm{m} / \mathrm{slice}$; scales in 1- 4 are $40 \mu \mathrm{m}) . \boldsymbol{e}$, Localization of cholinergic neurons in the nucleus basalis of Meynert (nbM), the substantia innominata (SI), and the horizontal nucleus of the diagonal band and the magnocellular preoptic region (HDB/MCPO). GP, Globus pallidus, (Pu, caudate-putamen. Green square represents the location of the slices $1-4$ in $\boldsymbol{a}$ and $\boldsymbol{b}$ in the ventral nbM. There are two residual neurons in $\boldsymbol{b}$ (arrows). $\boldsymbol{c}, \boldsymbol{d}, \mathrm{VAChT}$-positive varicosities in the parietal cortex of the same rat (e, green square for location of the consecutive slices 1-4 shown in c [5.66 $\mu \mathrm{m} / \mathrm{slice}]$ and $\boldsymbol{d}[5.30 \mu \mathrm{m} / \mathrm{slice}])$. Analysis of immunoreactive puncta in the cortex indicted a $75 \%$ loss in cholinergic innervation relative to control cortex. $\boldsymbol{f}$ ChAT-positive neurons on a coronal section from a sham rat brain. Red arrows indicate the needle tract from the sham surgery. The three regions of cholinergic neurons are indicated by lightly shaded areas (see also $\boldsymbol{e}$ ). The two framed regions represent the areas used to generate estimates of the density of (residual) cholinergic neurons (see Materials and Methods).

est), with median scores of 2.50 for 6-OHDA rats and 2.75 for DL rats (interquartile ranges: 1.5 . and 1.13 , respectively).

As described in Materials and Methods, a composite cholinergic-dopaminergic lesion score was generated to analyze the relationship between the two lesions in DL rats and falls. This combined lesion score correlated significantly with falls $\left(R^{2}=0.48 ; p=0.037\right)$. In contrast, individual cholinergic cell estimates in DL rats did not correlate with falls (nbM and HDB estimates; both $\left.R^{2}<0.03 ; p>0.73\right)$. Importantly, in DL rats, the dopaminergic lesion score alone correlated significantly with falls $\left(R^{2}=0.58 ; p=0.017\right)$. Analyzing the individual components of the dopaminergic lesion score indicated that the more the 6-OHDA lesions were placed in the prefrontal projection field and the larger they were the greater the number of falls (both $R^{2}>0.47$, both $p<0.04$ ). This finding contrasts with the absence of a correlation between the lesion score and falls in rats with 6-OHDA lesions only $\left(R^{2}=0.02\right.$; $p=0.68)$. 


\section{Discussion}

Our experiments demonstrated that rats with combined cortical cholinergic-striatal dopaminergic deafferentation (DL) exhibited an increased propensity for falls, assessed by a new behavioral apparatus, that fall rate and SAT performance correlated in DL rats, but not in rats with only cholinergic or dopaminergic lesions (SAP or 6-OHDA), that cholinergic cell loss correlated with SAT performance, and, importantly, that in DL rats the placement and size of the dopaminergic lesions correlated with fall rates. Here we discuss the validity of the behavioral test apparatus in terms of revealing fall propensity and the evidence in support of the conclusion that the increased fall rate in DL rats reflects the loss of attentional capacities to compensate for impairments in the striatal control of complex movement.

Across all MCMCT testing conditions involving rods, whether stationary or rotating, SAP and DL rats fell more frequently than shams and 6-OHDA rats. MCMCT performance by 6-OHDA rats did not differ from shams. In SAP rats, fall rates were only moderately increased over shams and when compared with the high rates in DL rats. Moreover, SAP rats did not fall more frequently than shams when traversing the stationary rod, but they reached fall rates that corresponded to those seen in DL rats when traversing the rod rotating at the less familiar clockwise direction (Fig. 5b). Traversing the clockwise-rotating rod presumably required major adaptions of gait and balance control, including counteracting the now reversed perpendicular (rightward) force of the rod. Moreover, performing this task required rats to modify the kinematic mechanisms used to rebalance after slips, including a shifting of the center of mass into the opposite direction than on the more familiar leftward turning rod. The finding that, in SAP rats, the number of slips was correlated with SAT perfor-

mance (Fig. $7 b$ ) supports the hypothesis that impairments in attention contributed to errors in complex movement, gait and balance, and therefore likely also to impaired rebalancing after slips (Allcock et al., 2009; LaPointe et al., 2010; O'Halloran et al., 2011; Yarnall et al., 2011; see also Martin et al., 2013).

DL rats fell more frequently across all MCMCT testing conditions. Slower forward movement, micropauses, "slouched" positions, and impaired rebalancing after slips were associated with falls. These symptoms in DL rats may model the postural instabilities and gait control deficits that are associated with falls in PD patients (Wood et al., 2002; Balash et al., 2005; Cole et al., 2011; Galna et al., 2013). Unexpectedly, traversing rods did not enhance fall rates if placed at inclines; indeed, when stationary and placed at inclines, rod performance improved over stationary, flat rod performance. It is
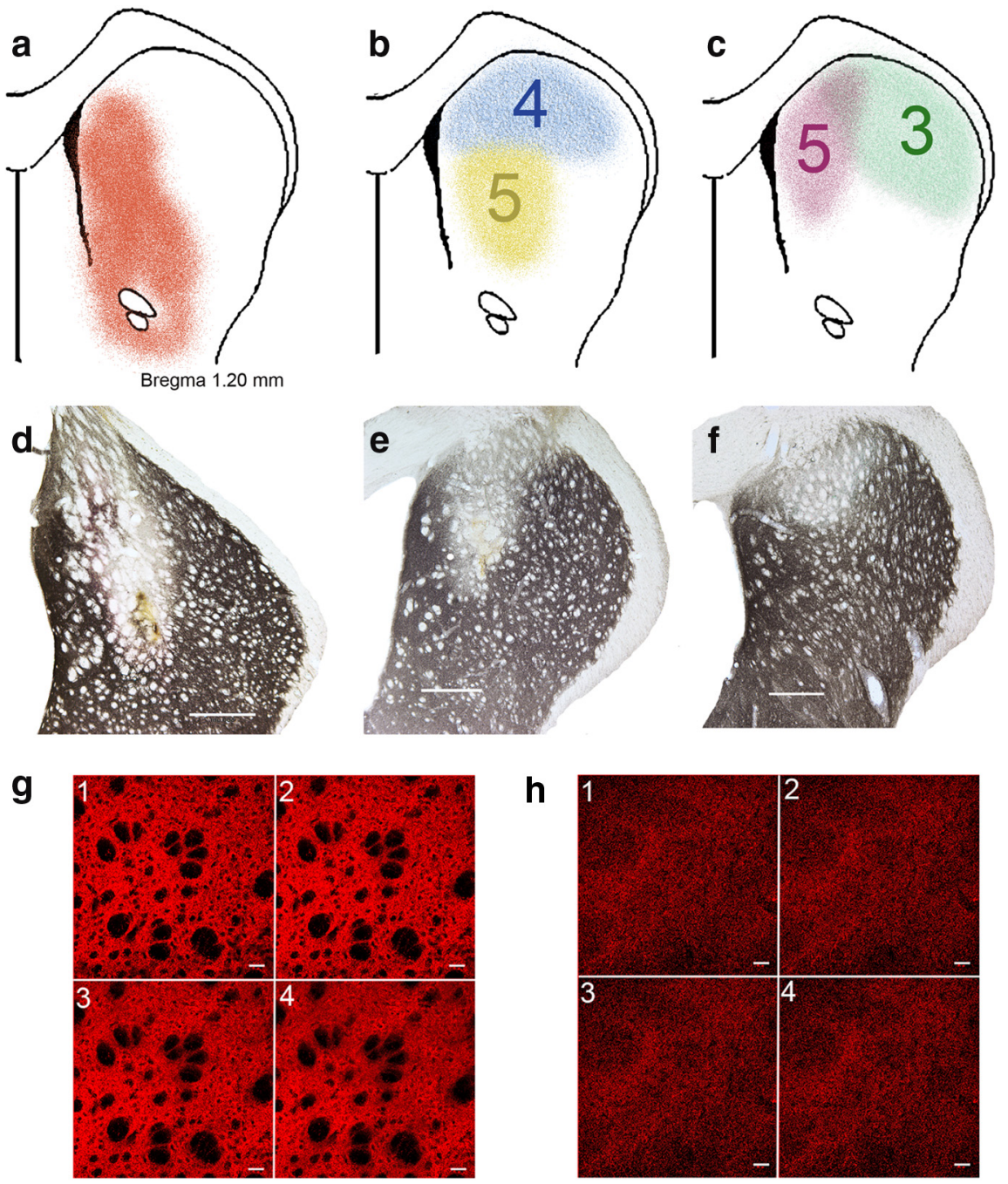

9. 6-OHDA-induced loss of TH immunoreactivity in the caudate nucleus. $\boldsymbol{a}$, Striatal projection region of the media Representative extensions of loss of TH immunoreactivity and rating of placements (5 [best] to 1; see Materials and Methods). The ellow and pink lesions received highest ratings for placement, whereas the deafferentation of the blue and green examples was fesioned hemispheres. Scale bars, $500 \mu \mathrm{m}$. To further exemplify the ratings of these lesions, $\boldsymbol{d}$ was rated 5 for placement and 5 fize (for definition, see Materials and Methods), $\boldsymbol{e}$ was rated 5 for placement and 2 for size, and $f$ received a 4 for placement and $4.71 \mu \mathrm{m} / \mathrm{slice}$ ) and a 6-0HDA-lesioned rat ( $\boldsymbol{h} ; 3.77 \mu \mathrm{m} / \mathrm{slice}$; scales in slices are $40 \mu \mathrm{m})$. Morphometric analyses of residual TH puncta indicated a consistently near complete $(>90 \%)$ reduction of TH immunofluorescence in the center of 6-0HDA lesions. In DL rats, the placement and size of the dopaminergic lesions correlated with fall rates.

not clear whether this beneficial effect of incline represents an advantage of quadrupedal locomotion or whether this particular task activated cognitive-behavioral resources to benefit performance. However, when rotating the rod, this benefit of incline was abolished (Fig. 4c), suggesting that it was not merely the result of the kinematic effects of uphill locomotion (e.g., Arnold et al., 2013).

We hypothesized that the greater propensity for falls in DL rats reflected a loss of attentional compensation of the deficits in the striatal control of the complex movements required to traverse stationary and rotating rods. First, a significant correlation between fall rate and the relative number of hits in the SAT was found only in DL rats (Fig. 7a; SAP and DL rats' SAT performance did not differ statistically). Furthermore, correlations between slips and hits, slips and falls, and falls and traversal speed were all significant in DL rats (Fig. 7), consistent with the view 
that the impairments in MCMCT performance were associated with their attentional deficits.

The second argument in support of this hypothesis is based on the analysis of the lesions and the relationships between the lesions and SAT and MCMCT performance. Dopaminergic lesions alone (6-OHDA rats) impaired neither SAT nor MCMCT performance. As shown in Figure 2a, 6-OHDA rats' SAT performance to the two shorter signals indeed was better than in all other groups. We speculate that the intact cholinergic system of 6-OHDA rats permitted such an overcompensatory attentional control in response to impaired habitual (striatal) control of performance (Redgrave et al., 2010; see also van Schouwenburg et al., 2012). Thus, the striatal deficit was "masked" by attentional mechanisms. However, in DL rats, fall rates were not correlated with cholinergic cell loss but with the placement and size of the dopaminergic lesions. In other words, dopaminergic deafferentation, that per se (6-OHDA rats) did not affect MCMCT performance, became the sole predictor of fall rates when combined with cortical cholinergic deafferentation. We interpret this finding as indicating that, in the presence of attentional control deficits, impairments in the striatal control of complex movements, gait and balance, are "unmasked." If correct, this hypothesis would predict upregulated tonic cholinergic mediation of SAT performance in 6-OHDA rats (Sarter and Paolone, 2011; see also St Peters et al., 2011; Paolone et al., 2013).

Once "unmasked" by cholinergic lesions, slow traversal performance, lower step frequency, "slouched posture," and impaired rebalancing after slips, and thus falls, characterized the MCMCT performance of rats with striatal dopamine loss (see comparable effects on posture and step size in rats with large dopamine lesions treated with an anticholinergic drug) (Pellis et al., 1987). These observations are consistent with evidence indicating that striatal circuitry integrates the cognitive-motivational aspects of goal-oriented behavior (Kim et al., 2013; Wang et al., 2013), including the sequencing of current versus future movement plans (Bhutani et al., 2013), with habitual support for such behaviors (see also Graybiel, 2008; Smith et al., 2012). The unmasking of these functions by cortical cholinergic deafferentation, as well as the seemingly paradoxical enhancement of SAT performance in 6-OHDA rats, is broadly consistent with the proposal that prefrontal-striatal systems are competitive, albeit interacting, systems for flexible, experience-based performance and for computationally more simplistic, habit-based performance, respectively (Daw et al., 2005).

We expected that the door frame and FL distractors would disproportionally increase the number of falls in DL rats. This was not the case. The distractors increased falls in all animals but more so in shams and 6-OHDA rats than in SAP and DL rats, abolishing statistical differences seen in the absence of distractors. As described in Results, in trials not ending with falls and, in case of the FL distractor not involving FL retrieval, the distractors slowed traversal time in shams and 6-OHDA rats, but not in SAP and DL rats. We interpret these data as suggesting that, as a result of cholinergic lesions, processing of the distractors was diminished. Our previous finding supports the view that prefrontal cholinergic deafferentation attenuates the frequency and amplitude of distractor-evoked prefrontal neuronal activity (Gill et al., 2000). Alternatively, and as DL rats fell in close to $60 \%$ of trials in the absence of distractors, we cannot rule out that "ceiling effects" for falls limited the demonstration of even greater fall rates in response to distractors.

As discussed, the present lesions were guided by evidence indicating that decreases in cholinergic activity in the cortex of PD patients are associated with increased fall risk (Bohnen and Albin, 2009; Bohnen et al., 2009) and the intent to reproduce the limited striatal dopamine loss seen early in PD (Sawamoto et al., 2008). Although it may be considered more valid to study the mechanisms of fall propensity in a full model of PD, the primary sensorimotor consequences of large or even unilateral dopamine lesions (for review, see Meredith and Kang, 2006; Simola et al., 2007) would enormously complicate the neuronal, behavioral, and cognitive interpretation of changes in fall propensity. The goal of this research is to determine specifically the cognitivebehavioral symptoms associated with loss in multiple neuronal systems (Langston, 2006), rather than focusing on developing a comprehensive model of the disease. It will be important to also assess the contributions of another cholinergic pathway, originating in the pendunculopontine nucleus and projecting to the dopaminergic midbrain and thalamus, to complex movement dysfunctions and falls (Bohnen et al., 2009; Karachi et al., 2010; Grabli et al., 2013).

An interesting corollary prediction from our results is that anti-cholinergic agents may have particularly adverse effects on postural stability in PD patients, especially under demanding gait conditions or when confronted with distractions. Anti-muscarinic cholinergic agents are used, albeit with decreasing frequency, primarily to treat tremor in PD. The contribution of anticholinergic drugs to falls in the elderly is well established (Aizenberg et al., 2002). Similar studies have not, however, been performed in PD patients. Studying the effects of cholinergic agents on gait and postural control under demanding conditions in PD subjects may be useful in further dissecting the role of cholinergic systems in gait and balance functions. Nicotinic drugs have been demonstrated to benefit SAT performance (Howe et al., 2010) and, thus, in interaction with potentially relatively low doses of L-DOPA, may benefit the nonmotor symptoms of PD (Schneider et al., 1998, 1999, 2003; Decamp and Schneider, 2009).

\section{References}

Aizenberg D, Sigler M, Weizman A, Barak Y (2002) Falls among elderly psychiatric inpatients: a 4-year case-control Study. Int Psychogeriatr 14: 307-310. CrossRef Medline

Allcock LM, Rowan EN, Steen IN, Wesnes K, Kenny RA, Burn DJ (2009) Impaired attention predicts falling in Parkinson's disease. Parkinsonism Relat Disord 15:110-115. CrossRef Medline

Allred RP, Adkins DL, Woodlee MT, Husbands LC, Maldonado MA, Kane JR, Schallert T, Jones TA (2008) The vermicelli handling test: a simple quantitative measure of dexterous forepaw function in rats. J Neurosci Methods 170:229-244. CrossRef Medline

Arnold AS, Lee DV, Biewener AA (2013) Modulation of joint moments and work in the goat hindlimb with locomotor speed and surface grade. J Exp Biol 216:2201-2212. CrossRef Medline

Balash Y, Peretz C, Leibovich G, Herman T, Hausdorff JM, Giladi N (2005) Falls in outpatients with Parkinson's disease: frequency, impact and identifying factors. J Neurol 252:1310-1315. CrossRef Medline

Beal MF (2010) Parkinson's disease: a model dilemma. Nature 466:S8-S10. CrossRef Medline

Bhutani N, Sureshbabu R, Farooqui AA, Behari M, Goyal V, Murthy A (2013) Queuing of concurrent movement plans by basal ganglia. J Neurosci 33:9985-9997. CrossRef Medline

Bohnen NI, Albin RL (2009) Cholinergic denervation occurs early in Parkinson disease. Neurology 73:256-257. CrossRef Medline

Bohnen NI, Albin RL (2011) The cholinergic system and Parkinson disease. Behav Brain Res 221:564-573. CrossRef Medline

Bohnen NI, Kaufer DI, Ivanco LS, Lopresti B, Koeppe RA, Davis JG, Mathis CA, Moore RY, DeKosky ST (2003) Cortical cholinergic function is more severely affected in parkinsonian dementia than in Alzheimer disease: an in vivo positron emission tomographic study. Arch Neurol 60: 1745-1748. CrossRef Medline 
Bohnen NI, Müller ML, Koeppe RA, Studenski SA, Kilbourn MA, Frey KA, Albin RL (2009) History of falls in Parkinson disease is associated with reduced cholinergic activity. Neurology 73:1670-1676. CrossRef Medline

Bohnen NI, Müller ML, Kotagal V, Koeppe RA, Kilbourn MR, Gilman S, Albin RL, Frey KA (2012) Heterogeneity of cholinergic denervation in Parkinson's disease without dementia. J Cereb Blood Flow Metab 32: 1609-1617. CrossRef Medline

Botly LC, De Rosa E (2009) Cholinergic deafferentation of the neocortex using 192 IgG-saporin impairs feature binding in rats. J Neurosci 29: 4120-4130. CrossRef Medline

Breese GR, Traylor TD (1971) Depletion of brain noradrenaline and dopamine by 6-hydroxydopamine. Br J Pharmacol 42:88-99. CrossRef Medline

Burk JA, Herzog CD, Porter MC, Sarter M (2002) Interactions between aging and cortical cholinergic deafferentation on attention. Neurobiol Aging 23:467-477. CrossRef Medline

Cole MH, Silburn PA, Wood JM, Worringham CJ, Kerr GK (2010) Falls in Parkinson's disease: kinematic evidence for impaired head and trunk control. Mov Disord 25:2369-2378. CrossRef Medline

Cole MH, Silburn PA, Wood JM, Kerr GK (2011) Falls in Parkinson's disease: evidence for altered stepping strategies on compliant surfaces. Parkinsonism Relat Disord 17:610-616. CrossRef Medline

Cools R, Rogers R, Barker RA, Robbins TW (2010) Top-down attentional control in Parkinson's disease: salient considerations. J Cogn Neurosci 22:848-859. CrossRef Medline

Cowie D, Limousin P, Peters A, Hariz M, Day BL (2012) Doorwayprovoked freezing of gait in Parkinson's disease. Mov Disord 27:492-499. CrossRef Medline

Dalley JW, Theobald DE, Bouger P, Chudasama Y, Cardinal RN, Robbins TW (2004) Cortical cholinergic function and deficits in visual attentional performance in rats following $192 \mathrm{IgG}$-saporin-induced lesions of the medial prefrontal cortex. Cereb Cortex 14:922-932. CrossRef Medline

Daw ND, Niv Y, Dayan P (2005) Uncertainty-based competition between prefrontal and dorsolateral striatal systems for behavioral control. Nat Neurosci 8:1704-1711. CrossRef Medline

Decamp E, Schneider JS (2009) Interaction between nicotinic and dopaminergic therapies on cognition in a chronic Parkinson model. Brain Res 1262:109-114. CrossRef Medline

Demeter E, Sarter M, Lustig C (2008) Rats and humans paying attention: cross-species task development for translational research. Neuropsychology 22:787-799. CrossRef Medline

Demeter E, Hernandez-Garcia L, Sarter M, Lustig C (2011) Challenges to attention: a continuous arterial spin labeling (ASL) study of the effects of distraction on sustained attention. Neuroimage 54:1518-1529. CrossRef Medline

Demeter E, Guthrie SK, Taylor SF, Sarter M, Lustig C (2013) Increased distractor vulnerability but preserved vigilance in patients with schizophrenia: evidence from a translational Sustained Attention Task. Schizophr Res 144:136-141. CrossRef Medline

Drucker-Colín R, García-Hernández F (1991) A new motor test sensitive to aging and dopaminergic function. J Neurosci Methods 39:153-161. CrossRef Medline

Fleming SM (2009) Behavioral outcome measures for the assessment of sensorimotor function in animal models of movement disorders. Int Rev Neurobiol 89:57-65. CrossRef Medline

Frey PW, Colliver JA (1973) Sensitivity and responsivity measures for discrimination learning. Learn Motivation 4:327-342. CrossRef

Galna B, Murphy AT, Morris ME (2013) Obstacle crossing in Parkinson's disease: mediolateral sway of the centre of mass during level-ground walking and obstacle crossing. Gait Posture. Advance online publication. Retrieved May 3, 2013. doi: 10.1016/j.gaitpost.2013.03.024. CrossRef

Gill TM, Sarter M, Givens B (2000) Sustained visual attention performanceassociated prefrontal neuronal activity: evidence for cholinergic modulation. J Neurosci 20:4745-4757. Medline

Grabli D, Karachi C, Folgoas E, Monfort M, Tande D, Clark S, Civelli O, Hirsch EC, François C (2013) Gait disorders in Parkinsonian monkeys with pedunculopontine lesions: a tale of two systems. J Neurosci 33: 11986-11993. CrossRef Medline

Graybiel AM (2008) Habits, rituals, and the evaluative brain. Annu Rev Neurosci 31:359-387. CrossRef Medline

Greenwald AG, Gonzalez R, Harris RJ, Guthrie D (1996) Effect sizes and p values: What should be reported and what should be replicated? Psychophysiology 33:175-183. CrossRef Medline

Hall CD, Echt KV, Wolf SL, Rogers WA (2011) Cognitive and motor mechanisms underlying older adults' ability to divide attention while walking. Phys Ther 91:1039-1050. CrossRef Medline

Howe WM, Ji J, Parikh V, Williams S, Mocaër E, Trocmé-Thibierge C, Sarter M (2010) Enhancement of attentional performance by selective stimulation of alpha4beta $2^{\star}$ nAChRs: underlying cholinergic mechanisms. Neuropsychopharmacology 35:1391-1401. CrossRef Medline

Howe WM, Berry AS, Francois J, Gilmour G, Carp JM, Tricklebank M, Lustig C, Sarter M (2013) Prefrontal cholinergic mechanisms instigating shifts from monitoring for cues to cue-guided performance: converging electrochemical and fMRI evidence from rats and humans. J Neurosci 33: 8742-8752. CrossRef Medline

Hwang DY, Fleming SM, Ardayfio P, Moran-Gates T, Kim H, Tarazi FI, Chesselet MF, Kim KS (2005) 3,4-Dihydroxyphenylalanine reverses the motor deficits in Pitx3-deficient aphakia mice: behavioral characterization of a novel genetic model of Parkinson's disease. J Neurosci 25:21322137. CrossRef Medline

Ikonomovic MD, Mufson EJ, Wuu J, Bennett DA, DeKosky ST (2005) Reduction of choline acetyltransferase activity in primary visual cortex in mild to moderate Alzheimer's disease. Arch Neurol 62:425-430. CrossRef Medline

Johnell O, Melton LJ 3rd, Atkinson EJ, O'Fallon WM, Kurland LT (1992) Fracture risk in patients with parkinsonism: a population-based study in Olmsted County, Minnesota. Age Ageing 21:32-38. CrossRef Medline

Karachi C, Grabli D, Bernard FA, Tandé D, Wattiez N, Belaid H, Bardinet E, Prigent A, Nothacker HP, Hunot S, Hartmann A, Lehéricy S, Hirsch EC, François C (2010) Cholinergic mesencephalic neurons are involved in gait and postural disorders in Parkinson disease. J Clin Invest 120:27452754. CrossRef Medline

Kim H, Lee D, Jung MW (2013) Signals for previous goal choice persist in the dorsomedial, but not dorsolateral striatum of rats. J Neurosci 33:5263. CrossRef Medline

Langston JW (2006) The Parkinson's complex: parkinsonism is just the tip of the iceberg. Ann Neurol 59:591-596. CrossRef Medline

LaPointe LL, Stierwalt JA, Maitland CG (2010) Talking while walking: cognitive loading and injurious falls in Parkinson's disease. Int J Speech Lang Pathol 12:455-459. CrossRef Medline

Litvan I, Goldman JG, Tröster AI, Schmand BA, Weintraub D, Petersen RC, Mollenhauer B, Adler CH, Marder K, Williams-Gray CH, Aarsland D, Kulisevsky J, Rodriguez-Oroz MC, Burn DJ, Barker RA, Emre M (2012) Diagnostic criteria for mild cognitive impairment in Parkinson's disease: Movement Disorder Society Task Force guidelines. Mov Disord 27:349356. CrossRef Medline

Lord S, Rochester L, Hetherington V, Allcock LM, Burn D (2010) Executive dysfunction and attention contribute to gait interference in 'off state Parkinson's Disease. Gait Posture 31:169-174. CrossRef Medline

Lu XH, Fleming SM, Meurers B, Ackerson LC, Mortazavi F, Lo V, Hernandez D, Sulzer D, Jackson GR, Maidment NT, Chesselet MF, Yang XW (2009) Bacterial artificial chromosome transgenic mice expressing a truncated mutant parkin exhibit age-dependent hypokinetic motor deficits, dopaminergic neuron degeneration, and accumulation of proteinase $k$-resistant $\alpha$-synuclein. J Neurosci 29:1962-1976. CrossRef Medline

Luiten PG, Gaykema RP, Traber J, Spencer DG Jr (1987) Cortical projection patterns of magnocellular basal nucleus subdivisions as revealed by anterogradely transported Phaseolus vulgaris leucoagglutinin. Brain Res 413:229-250. CrossRef Medline

Lundblad M, Andersson M, Winkler C, Kirik D, Wierup N, Cenci MA (2002) Pharmacological validation of behavioural measures of akinesia and dyskinesia in a rat model of Parkinson's disease. Eur J Neurosci 15:120-132. CrossRef Medline

Lundblad M, Picconi B, Lindgren H, Cenci MA (2004) A model of L-DOPAinduced dyskinesia in 6-hydroxydopamine lesioned mice: relation to motor and cellular parameters of nigrostriatal function. Neurobiol Dis 16: 110-123. CrossRef Medline

Mailly P, Aliane V, Groenewegen HJ, Haber SN, Deniau JM (2013) The rat prefrontostriatal system analyzed in 3D: evidence for multiple interacting functional units. J Neurosci 33:5718-5727. CrossRef Medline

Martin KL, Blizzard L, Srikanth VK, Wood A, Thomson R, Sanders LM, Callisaya ML (2013) Cognitive function modifies the effect of physio- 
logical function on the risk of multiple falls: a population-based study. J Gerontol A Biol Sci Med Sci 68:1091-1097. CrossRef Medline

Mattila PM, Röyttä M, Lönnberg P, Marjamäki P, Helenius H, Rinne JO (2001) Choline acetyltransferase activity and striatal dopamine receptors in Parkinson's disease in relation to cognitive impairment. Acta Neuropathol 102:160-166. Medline

McDowell K, Chesselet MF (2012) Animal models of the non-motor features of Parkinson's disease. Neurobiol Dis 46:597-606. CrossRef Medline

McGaughy J, Sarter M (1995) Behavioral vigilance in rats: task validation and effects of age, amphetamine, and benzodiazepine receptor ligands. Psychopharmacology (Berl) 117:340-357. CrossRef Medline

McGaughy J, Sarter M (1998) Sustained attention performance in rats with intracortical infusions of 192 IgG-saporin-induced cortical cholinergic deafferentation: effects of physostigmine and FG 7142. Behav Neurosci 112:1519-1525. CrossRef Medline

McGaughy J, Kaiser T, Sarter M (1996) Behavioral vigilance following infusions of 192 IgG-saporin into the basal forebrain: selectivity of the behavioral impairment and relation to cortical AChE-positive fiber density. Behav Neurosci 110:247-265. CrossRef Medline

McGaughy J, Decker MW, Sarter M (1999) Enhancement of sustained attention performance by the nicotinic acetylcholine receptor agonist ABT418 in intact but not basal forebrain-lesioned rats. Psychopharmacology (Berl) 144:175-182. CrossRef Medline

Meredith GE, Kang UJ (2006) Behavioral models of Parkinson's disease in rodents: a new look at an old problem. Mov Disord 21:1595-1606. CrossRef Medline

Metz GA, Whishaw IQ (2009) The Ladder Rung Walking Task: a scoring system and its practical application. J Vis. Exp 28:1-4.

Mohr F, Zimmermann M, Klein J (2013) Mice heterozygous for AChE are more sensitive to AChE inhibitors but do not respond to BuChE inhibition. Neuropharmacology 67:37-45. CrossRef Medline

Montoya CP, Campbell-Hope LJ, Pemberton KD, Dunnett SB (1991) The "staircase test": a measure of independent forelimb reaching and grasping abilities in rats. J Neurosci Methods 36:219-228. CrossRef Medline

Naismith SL, Shine JM, Lewis SJ (2010) The specific contributions of setshifting to freezing of gait in Parkinson's disease. Mov Disord 25:10001004. CrossRef Medline

Nakano I, Hirano A (1984) Parkinson's disease: neuron loss in the nucleus basalis without concomitant Alzheimer's disease. Ann Neurol 15:415418. CrossRef Medline

Nilsson MH, Hariz GM, Iwarsson S, Hagell P (2012) Walking ability is a major contributor to fear of falling in people with Parkinson's disease: implications for rehabilitation. Parkinsons Dis 2012:1-7. CrossRef Medline

O’Halloran AM, Pénard N, Galli A, Fan C, Robertson IH, Kenny R (2011) Falls and falls efficacy: the role of sustained attention in older adults. BMC Geriatr 11:1-10. CrossRef Medline

Paolone G, Angelakos CC, Meyer PJ, Robinson TE, Sarter M (2013) Cholinergic control over attention in rats prone to attribute incentive salience to reward cues. J Neurosci 33:8321-8335. CrossRef Medline

Pellis SM, Pellis VC, Chesire RM, Rowland N, Teitelbaum P (1987) Abnormal gait sequence in locomotion after atropine treatment of catecholaminedeficient akinetic rats. Proc Natl Acad Sci U S A 84:8750-8753. CrossRef Medline

Plotnik M, Giladi N, Hausdorff JM (2012) Is freezing of gait in Parkinson's disease a result of multiple gait impairments? Implications for treatment. Parkinson's Dis 2012:1-8. CrossRef Medline

Redgrave P, Rodriguez M, Smith Y, Rodriguez-Oroz MC, Lehericy S, Bergman H, Agid Y, DeLong MR, Obeso JA (2010) Goal-directed and habitual control in the basal ganglia: implications for Parkinson's disease. Nat Rev Neurosci 11:760-772. CrossRef Medline

Sarter M, Paolone G (2011) Deficits in attentional control: cholinergic mechanisms and circuitry-based treatment approaches. Behav Neurosci 125:825-835. CrossRef Medline

Sawamoto N, Piccini P, Hotton G, Pavese N, Thielemans K, Brooks DJ (2008) Cognitive deficits and striato-frontal dopamine release in Parkinson's disease. Brain 131:1294-1302. CrossRef Medline

Schallert T, Woodlee MT (2005) Orienting and placing. In: The behavior of the laboratory rat: a handbook with tests (Whishaw I, Kolb B, eds), pp 129-140. Oxford: Oxford UP.

Schneider JS, Van Velson M, Menzaghi F, Lloyd GK (1998) Effects of the nicotinic acetylcholine receptor agonist SIB-1508Y on object retrieval performance in MPTP-treated monkeys: comparison with levodopa treatment. Ann Neurol 43:311-317. CrossRef Medline

Schneider JS, Tinker JP, Van Velson M, Menzaghi F, Lloyd GK (1999) Nicotinic acetylcholine receptor agonist SIB-1508Y improves cognitive functioning in chronic low-dose MPTP-treated monkeys. J Pharmacol Exp Ther 290:731-739. Medline

Schneider JS, Tinker JP, Menzaghi F, Lloyd GK (2003) The subtypeselective nicotinic acetylcholine receptor agonist SIB-1553A improves both attention and memory components of a spatial working memory task in chronic low dose 1-methyl-4-phenyl-1,2,3,6-tetrahydropyridinetreated monkeys. J Pharmacol Exp Ther 306:401-406. CrossRef Medline

Shimada H, Hirano S, Shinotoh H, Aotsuka A, Sato K, Tanaka N, Ota T, Asahina M, Fukushi K, Kuwabara S, Hattori T, Suhara T, Irie T (2009) Mapping of brain acetylcholinesterase alterations in Lewy body disease by PET. Neurology 73:273-278. CrossRef Medline

Simola N, Morelli M, Carta AR (2007) The 6-hydroxydopamine model of Parkinson's disease. Neurotox Res 11:151-167. CrossRef Medline

Smith KS, Virkud A, Deisseroth K, Graybiel AM (2012) Reversible online control of habitual behavior by optogenetic perturbation of medial prefrontal cortex. Proc Natl Acad Sci U S A 109:18932-18937. CrossRef Medline

Stam CJ, Visser SL, Op de Coul AA, De Sonneville LM, Schellens RL, Brunia CH, de Smet JS, Gielen G (1993) Disturbed frontal regulation of attention in Parkinson's disease. Brain 116:1139-1158. CrossRef Medline

St Peters M, Demeter E, Lustig C, Bruno JP, Sarter M (2011) Enhanced control of attention by stimulating mesolimbic-corticopetal cholinergic circuitry. J Neurosci 31:9760-9771. CrossRef Medline

Tennant KA, Asay AL, Allred RP, Ozburn AR, Kleim JA, Jones TA (2010) The vermicelli and capellini handling tests: simple quantitative measures of dexterous forepaw function in rats and mice. J Vis Exp 41:1-5. CrossRef Medline

Turchi J, Sarter M (2000) Cortical cholinergic inputs mediate processing capacity: effects of 192 IgG-saporin-induced lesions on olfactory span performance. Eur J Neurosci 12:4505-4514. CrossRef Medline

van Schouwenburg MR, O'Shea J, Mars RB, Rushworth MF, Cools R (2012) Controlling human striatal cognitive function via the frontal cortex. J Neurosci 32:5631-5637. CrossRef Medline

Wallace JE, Krauter EE, Campbell BA (1980) Motor and reflexive behavior in the aging rat. J Gerontol 35:364-370. CrossRef Medline

Wang AY, Miura K, Uchida N (2013) The dorsomedial striatum encodes net expected return, critical for energizing performance vigor. Nat Neurosci 16:639-647. CrossRef Medline

Whishaw IQ, Sacrey LA, Gorny B (2009) Hind limb stepping over obstacles in the horse guided by place-object memory. Behav Brain Res 198:372379. CrossRef Medline

Wood BH, Bilclough JA, Bowron A, Walker RW (2002) Incidence and prediction of falls in Parkinson's disease: a prospective multidisciplinary study. J Neurol Neurosurg Psychiatry 72:721-725. CrossRef Medline

Yarnall A, Rochester L, Burn DJ (2011) The interplay of cholinergic function, attention, and falls in Parkinson's disease. Mov Disord 26:24962503. CrossRef Medline

Zigmond MJ, Stricker EM (1989) Animal models of parkinsonism using selective neurotoxins: clinical and basic implications. Int Rev Neurobiol 31:1-79. CrossRef Medline 